\title{
Clinical Applications of Optical Coherence Tomography in Ophthalmology
}

\author{
Upender K. Wali and Nadia Al Kharousi \\ College of Medicine and Health Sciences, Sultan Qaboos University \\ Oman
}

"In Ophthalmology, one who relies on Optical Coherence Tomography (OCT) alone is little wise, one who relies on OCT and Fluorescein angiography is wiser, and one who relies on $O C T$, angiography and clinical examination is the wisest."

\section{Introduction}

Optical coherence tomography (OCT) was first reported in 1991 as a non-invasive ocular imaging technology (Huang et al, 1991; Hrynchak \& Simpson, 2007). It generates a false-color representation of the tissue structures, based on the intensity of the returned light. Over years, the clinical applications of OCT have improved dramatically in precision and specificity. It has been compared to an in vivo optical biopsy. As the resolution of OCT has been getting more and more refined, the identification, detection, localization and quantification of the tissues has accordingly, become more superior and reliable (Ryan SJ, 2006). There are several nonophthalmic applications of OCT as well, but this chapter shall focus on its clinical applications in ocular diseases alone (Aguirre et al., 2003; Fujimoto, 2003).

\section{Basic applications of optical coherence tomography in eye disorders:}

Before we proceed with the clinical part of this chapter, let us have the basic information about the OCT scan and the tissues, which would permit comprehensive interpretation of the text and the abnormal images from pathologic tissues. Different models of OCT machines are in use ranging from Stratus (resolution 10 microns) to Cirrus-HD (resolution 5 microns) to ultrahigh-resolution models (resolution 2-3 microns, Drexler et al., 1999, 2001). To refresh our knowledge, we mention about the normal values first; these values help to interpret OCT scans in a better way:

- Distance between vitreoretinal interface and anterior surface of retinal pigment epithelium (RPE): 200 - 275 microns.

- Mean thickness in the foveal region: 170 - 190 microns.

- Mean thickness in peripheral retina: 220 - 280 microns.

- Mean thickness of retinal nerve fiber layer (RNFL): 270 microns (1000 microns from fovea where nerve fibers form a slight arcuate thickening).

- Normal retinal volume: 6-7 cubic mm. 
The OCT scan printouts bear pseudocolor imaging and retinal mapping is based on different color codes (white, red, orange, yellow, green, blue, and black in order), White being the thickest scanned retina (>470 microns) and black the thinnest scanned retina (<150 microns) [Hee et al., 2004]. However, such color imaging or color maps may vary for different models of OCT equipment. The macular thickness stock and color code distribution depicted here is for Cirrus 3D HD-OCT (Figure 1).

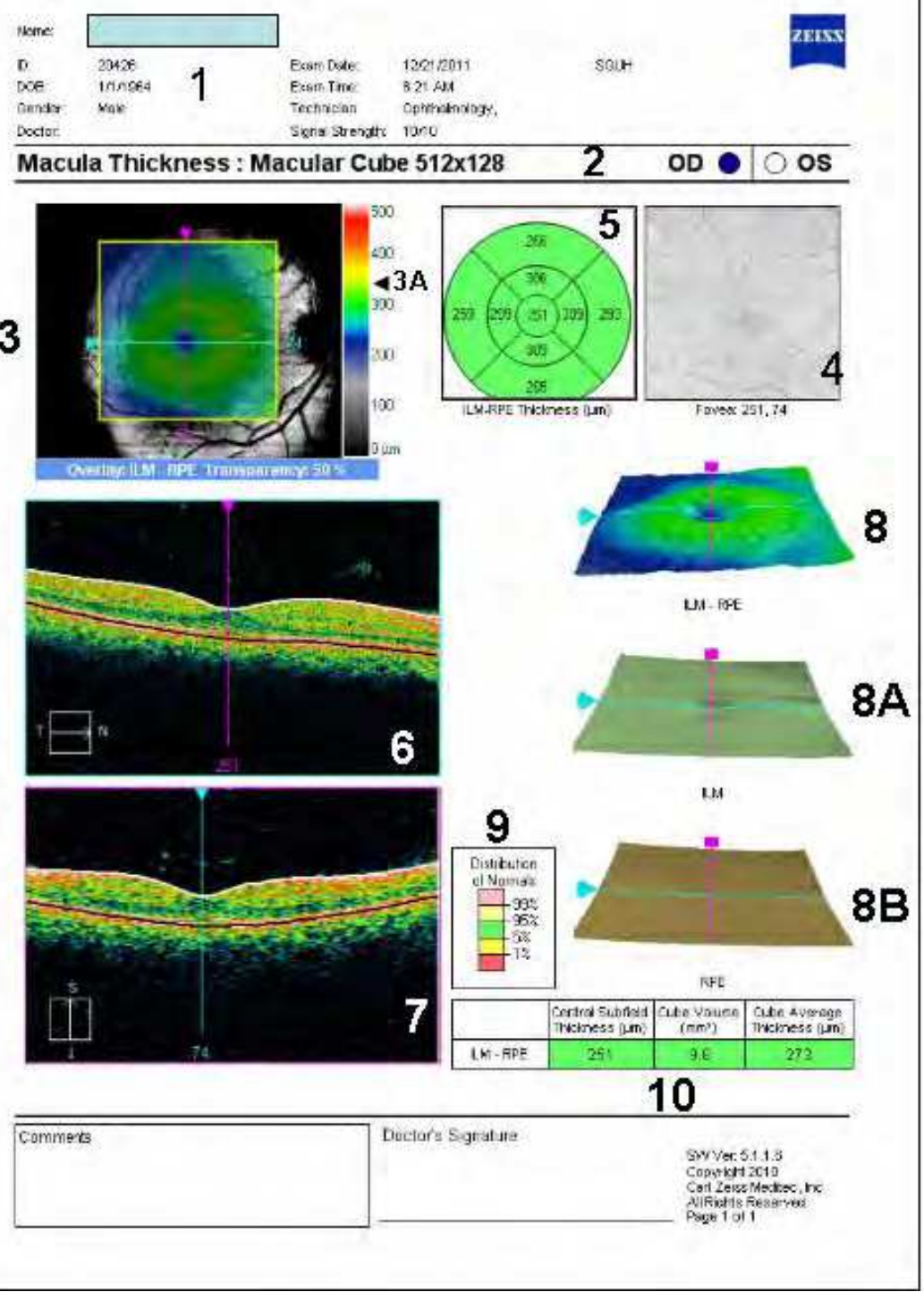

Fig. 1. OCT macular thickness stock printout. 
Section 1: Patient related data, examination date, list and signal strength. It is ideal to have minimum signal strength of 5 . If it is less, look for media opacities, dry cornea or a very small pupil.

Section 2: Indicates whether the scan is related to macula with its pixel strength (as in this picture) or optic disc cube (see figures 30,31). (It also displays the laterality of the eye: OD (right eye), OS (left eye).

Section 3: Fundus image with scan cube overlay. 3A: Color code for thickness overlays.

Section 4: OCT fundus image in grey shade. It shows the surface of the area over which the measurements were made.

Section 5: The circular map shows overall average thickness in nine sectors. It has three concentric circles representing diameters of $1 \mathrm{~mm}, 3 \mathrm{~mm}$ and $6 \mathrm{~mm}$, and except for the central circle, is divided into superior, nasal, inferior and temporal quadrants. The central circle has a radius of 500 micrometers.

Section 6: Slice through cube front. Temporal - nasal (left to right).

Section 7: Slice through cube side. Inferior - superior (left to right).

Section 8: Thickness between Internal limiting membrane (ILM) to retinal pigment epithelium (RPE) thickness map. 8A: Anterior layer (ILM). 8B: Posterior layer (RPE). All these are 3-D surface maps.

Section 9: Normative database uses color code to indicate normal distribution percentiles.

Section 10: Numerical average thickness and volume measurements. The central subfield thickness refers to the central circle of the circular map (section 5). The total volume and average thickness refer to the ILM-RPE tissue layer over the entire $6 \times 6 \mathrm{~mm}$ square scanned area.

Red and white - High reflectivity (long white arrow); black and blue - low reflectivity (yellow arrow); green - intermediate reflectivity (small white arrow). Normal retinal structures are labeled as: red for RNFL and junction of inner and outer segments of photoreceptors (PR); green for plexiform layers, and blue/black for nuclear layers. Both PR junctions and RPE are represented by red lines, former is thinner, later is thicker. An OCT scan should be read from left to right which ensures reading from temporal field to the nasal field for right eye and nasal to temporal in the left eye. It is not possible to identify the laterality of the eye from the macular scans. This should always be checked with fundus video image of the scan.

Light rays from OCT can remarkably penetrate ocular media opacities like mild cataract, mild posterior capsular opacification, mild vitreous hemorrhage, asteroid hyalosis and mild vitritis. In such cases, OCT can give gross macular details, though, a bit compromised in quality. One can go through beautiful OCT text and atlas for images with elaborate description in recommended books (Schuman et al., 2004).

The images in this chapter are from Cirrus 3D HD-OCT (except figure 17) which provides in-vivo viewing, axial cross-sectional 3-D images and measurement of posterior ocular structures. Cirrus HD has incorporated $>20 \%$ Asian individuals in its normative data base (unlike stratus OCT which has only 3\%). This is important as differences in RNFL thickness have been reported between various races (Poinooswamy et al., 1997). 


\subsection{A word to the OCT technicians}

- Miotic pupil, though not a deterrent to macular imaging, induces pupillary block of the incident light and hence affects two ends of the scan (Fujimoto et al., 2004). Mydriasis permits artifact free and a happy OCT procedure. A $3 \mathrm{~mm}$ pupil would leave both you and your patient smiling.

- Wheel less chair adds to the stability of the patient.

- Encourage patient to blink frequently during the procedure. Wet the cornea if required.

- Instruct the patient to look at the center of the green target, not at the moving red light of the scanning beam.

- Attempt to start with fast, low resolution, and then switch to high resolution scans quickly through areas of interest.

- Remind the ophthalmologist to have prior digital fundus photos and fluorescein angiography (FA) images for correlation with OCT scans later on.

- It is possible to image retina in a silicone oil filled eye, however, in gas filled eyes, it is possible to scan only after gas bubble has receded to $45 \%$ of the fill, when inferior meniscus has reached above the foveal level (Jumper et al., 2000; Sato et al., 2003).

- Ensure that the signal strength is five and above.

Optical coherence tomography provides both qualitative (morphology and reflectivity) and quantitative (thickness, mapping and volume) analyses of the examined tissues in-situ and in real time. The indications of OCT include posterior segment lesions like detection of fluid within the retinal layers or under the retina which may not be visible clinically (Kang et al., 2004; Margherio et al., 1989; McDonald et al., 1994; Smiddy et al., 1988), macular holes (Hikichi et al., 1995; Mavrofrides et al., 2005; Wilkins et al., 1996), pseudoholes (Hikichi et al., 1995), epiretinal membranes (ERMs) [Hikichi et al., 1995; Mori et al., 2004], vitreo-macular traction (VMT) [Kang et al., 2004; McDonald et al., 1994], retinoschisis (Eriksson et al., 2004), retinal detachment (Ip et al.,1999), diabetic retinopathy (DR) [Cruz-Villegas et al., 2004; Hee et al., 1998; Schaudig et al., 2000], age-related macular degeneration (ARMD) [Mavro frides et al. 2004], retinal nerve fiber layer thickness (RNFLT), optic disc parameters, and assessment and analysis of anterior segment structures like anterior chamber area, volume and iris thickness. OCT cannot be and should not be interpreted independently vis-à-vis any ocular disease. Also, it should never be taken as the only criteria for the diagnosis or treatment of any ocular disease. The ophthalmologist must have other information available such as valid perspectives of patient's systemic and ocular disease, fluorescein angiography (FA), indocyanine green angiography (ICGA), biomicroscopy, and above all, the relevant history of the disease process. For anterior segment surgeons, especially those involved in phacoemulsification, preoperative assessment of retinal integrity with OCT may be assuring to explain about conditions like ARMD, VMT, macular holes, and ERMs, in case patient's vision does not improve after uneventful cataract surgery. Changes in the reflectivity of tissue are important elements of OCT analysis. When pathology is present, this reflectivity may be increased (hyperreflectivity) or decreased (hyporeflectivity), or a shadow zone may be observed on the scan. The strength of the signal reflected by a specific tissue depends on properties like tissue reflectivity, the amount of light absorbed by the overlying tissues, and the amount of reflected light that reaches the sensor after it has been further attenuated by the interposed tissue. So when the strength of the reflected signal is strong, the scanned tissue has high reflectivity and vice-versa. The shadow effect represents an area of dense, highly refractile tissue that produces a screening effect, which 
may be complete or incomplete, thereby casting a shadow on an OCT scan that hides the elements behind it. The retinal structures can be hidden at various levels in the preretinal, intraretinal, and/or subretinal regions. Tables 1 and 2 give an elaborate description for these.

\begin{tabular}{|l|l|}
\hline Hyperreflective scans & Hyporeflective scans \\
\hline Drusen & Retinal atrophy \\
\hline ARMD & Intraretinal/subretinal fluid \\
\hline CNVM lesions & \\
\hline RNFL & \\
\hline ILM & \\
\hline RPE & \\
\hline RPE-choriocapillaries complex & \\
\hline PED & \\
\hline Anterior face of hemorrhage & \\
\hline Disciform scars & \\
\hline Hard Exudates & \\
\hline Epiretinal membrane & \\
\hline
\end{tabular}

Table 1. Reflectivity (signal strength) of OCT scans. (ARMD-age related macular degeneration; CNVM-choroidal neovascular membrane; RNFL-retinal nerve fiber layer; ILM-internal limiting membrane; RPE-retinal pigment epithelium; PED-pigment epithelial detachment).

\begin{tabular}{|l|l|}
\hline $\begin{array}{l}\text { Yes shadows (cone effect): } \\
\text { Superficial layers }\end{array}$ & No shadows. \\
\hline Normal retinal blood vessels & Serous collections \\
\hline Dense collection of blood & Scanty hemorrhage \\
\hline Cotton wool exudates & \\
\hline \multicolumn{1}{|c|}{ Deep layers } & \\
\hline Hard exudates (lipoproteins) & \\
\hline RPE hyperplasia & \\
\hline Intraocular foreign body & \\
\hline Dense pigmented scars & \\
\hline Choroidal nevi & \\
\hline Thick subretinal neovascular membranes & \\
\hline
\end{tabular}

Table 2. Shadow effects in Optical coherence tomography. (RPE-retinal pigment epithelium).

Vertical structures like PRs are less reflective than horizontal structures like RNFL or RPE layer. Other axially aligned cellular structures which show low tissue signals or reflectivity (represented by blue, green, yellow colors on OCT scans and printouts) are inner nuclear layer, outer nuclear layer and ganglion cell layers. This is due to reduced back-scattering and reduced back-reflection.

Normal ocular tissues which show high reflectivity are:

- Retinal nerve fiber layer.

- Internal limiting membrane.

- Junction between inner and outer segments of PRs, probably due to densely stacked disc membranes in outer segments (Hoang et al., 2002).

- Retinal pigment epithelium-Bruch's membrane-choriocapillaries complex. 
High reflectivity is a feature of reduced retinal thickness (as in retinal atrophy) and pigmentation of the scar tissue, example, a disciform scar. Lesions showing high reflectivity may be superficial, intraretinal or deep retinal.

\subsection{Superficial lesions}

- $\quad$ Epiretinal and vitreal membranes (Figure 2).

- Exudates and hemorrhages which produce an underlying shadow effect, if dense (Figure 3).

- Cotton wool spots which are exudates at the margin of recent ischemic areas (Figure 4).

\subsection{Intraretinal lesions}

- Hemorrhages. OCT should be set to a maximum resolution to elicit good scans (Figure $5)$.

- Hard exudates: these are lipoproteins located at the margin between healthy and edematous retina (Figure 6).

- $\quad$ Retinal fibrosis and disciform degenerative scars (Figure 7).

\subsection{Deep lesions}

- $\quad$ Drusen (Figure 8).

- Retinal pigment epithelial hyperplasia (Figure 9).

- Intraretinal and subretinal neovascular membranes (Figure 10)

- Scarring following choroiditis, trauma or laser treatment (Figure 11).

- Hyperpigmented choroidal nevi.

\subsection{Lesions causing hypo or low reflectivity}

- $\quad$ Atrophic RPE (loss of pigment).

- Cystic or pseudocystic areas containing serous fluid (Figure 12).

- Cystoid edema, serous neural retinal detachment (Figure 13) and RPE detachment. Such lesions appear as black, optically empty spaces.
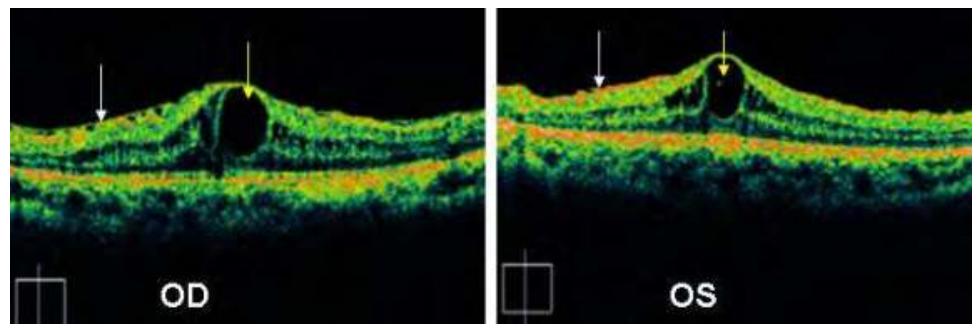

Fig. 2. Epiretinal membrane and cystoid macular edema in a patient with retinitis pigmentosa (Usher's syndrome). OCT in both eyes clearly defines hyperrefective epiretinal membranes (white arrows) which are attached to the internal limiting membranes (hyperreflective signal associated with white arrows). There is associated cystoid macular edema (yellow arrows). 

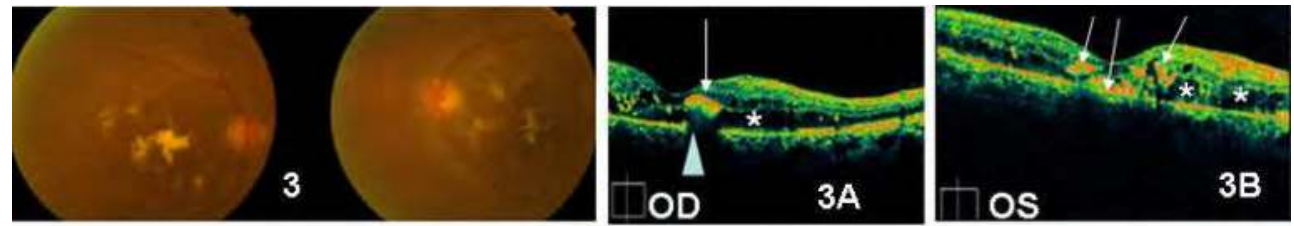

Fig. 3 Nonproliferative diabetic retinopathy. Fundus photo shows hard exudates in macular area in both eyes. 3A: OCT image of right eye: shows retinal edema (asterisk) and hard exudates in deeper retinal layers (white arrows). Note that what appears to be a missing chunk of RPE (arrowhead) is in fact shadow cast by overlying hard exudates (white arrow). 3B: OCT image of left eye showing multiple highly refractile intraretinal hard exudates (white arrows) and intraretinal edema as dark spaces (asterisks).

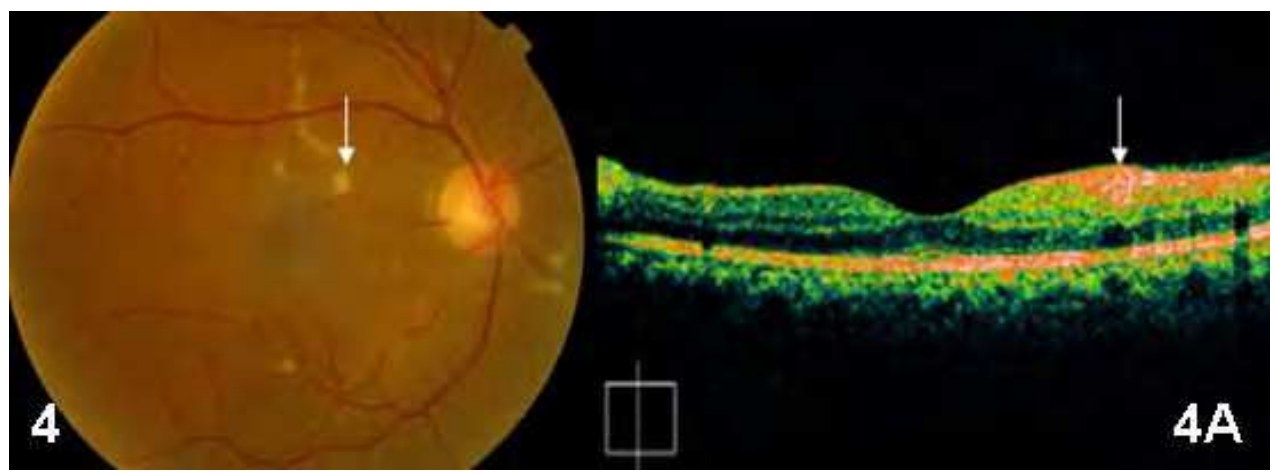

Fig. 4. Cotton wool exudates in a female diabetic patient. Fundus photo of right eye shows multiple yellowish-white soft cotton wool exudates (white arrow). 4A: OCT image has a hyperreflective signal from the exudate located nasal to the macula (white arrow).

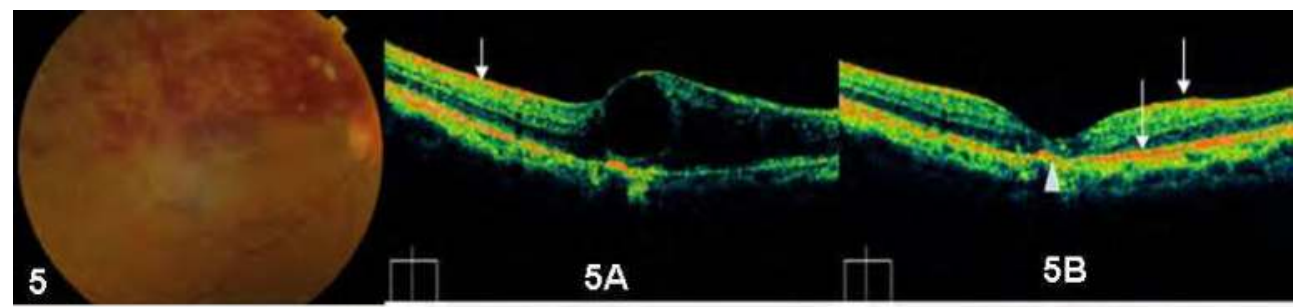

Fig. 5. Superior hemi-central venous occlusion (OD) in a 56 year old female. Fundus photo shows classical superficial and deep retinal hemorrhages. 5A: OCT image shows hyperreflective superficial hemorrhage (white arrow) and a large cystic swelling of the retina. 5B: OCT image of the same eye, six weeks after two intravitreal injections of bevacizumab shows completely resolved edema with residual subfoveal scarring (white arrow head). The hyperreflective signals (white arrows) from hemorrhages are still persisting. 


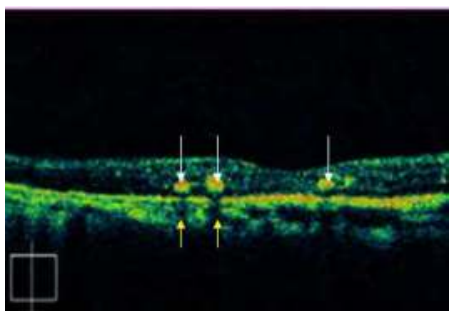

Fig. 6. Macular OCT scan of a female with diabetic retinopathy. The image (vertical scan) shows presence of hyperreflective hard exudates (white arrows) in deeper layers of retina casting underlying shadows (yellow arrows).
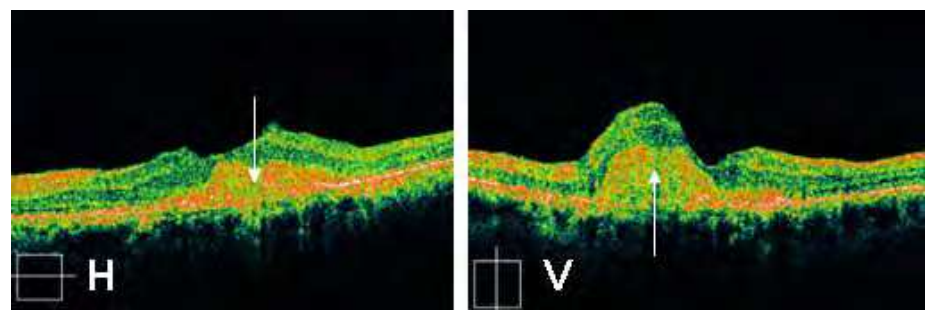

Fig. 7. Horizontal (H) and vertical (V) OCT scans showing hyperreflective subretinal scarring (Arrows) sequel to age related macular degeneration. Note the marked distortion of the macular surface.

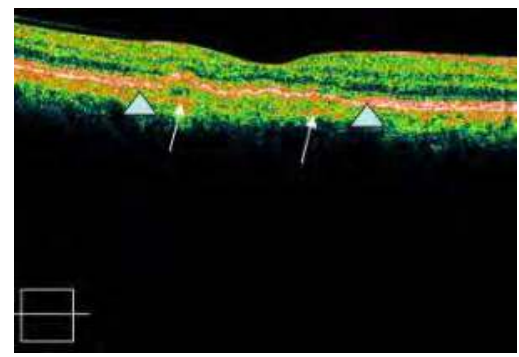

Fig. 8. Drusen. OCT image reveals hyperreflective signals from drusen under the RPE (white arrows). Note irregularity of the RPE contour in OCT (between arrowheads).

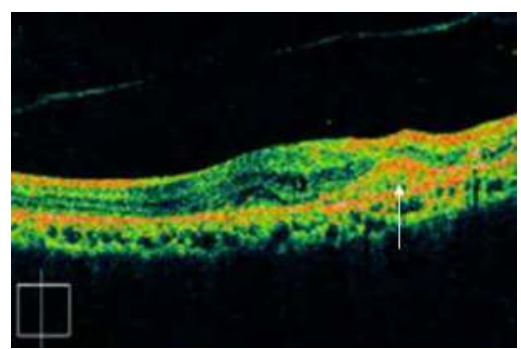

Fig. 9. Retinal pigment epithelial hyperplasia with hyperreflective signal (white arrow) in a case of ARMD. 

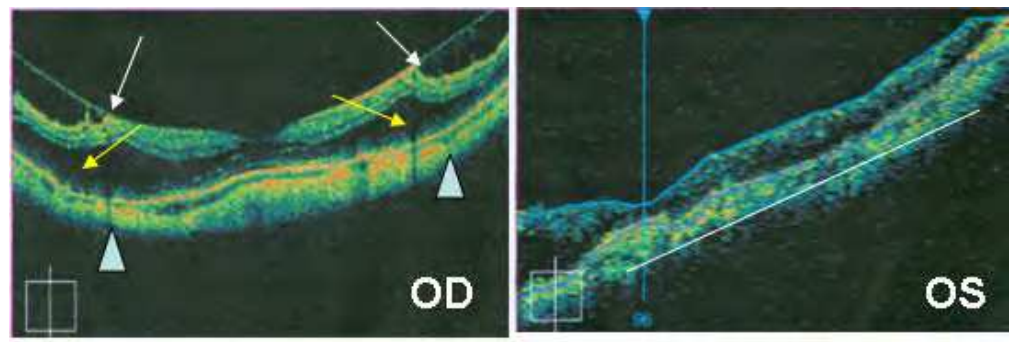

Fig. 10. Retinal vascular membranes (CNVM) with vitreo-macular traction and retinoschisis: OCT image of right eye (OD) shows residual CNVM (between arrowheads). There is VMT (white arrows) and retino-macular schisis (yellow arrows). Left eye (OS) OCT image depicts scarred CNVM (along line). There is VMT (white arrows) and retino-macular schisis (yellow arrows).

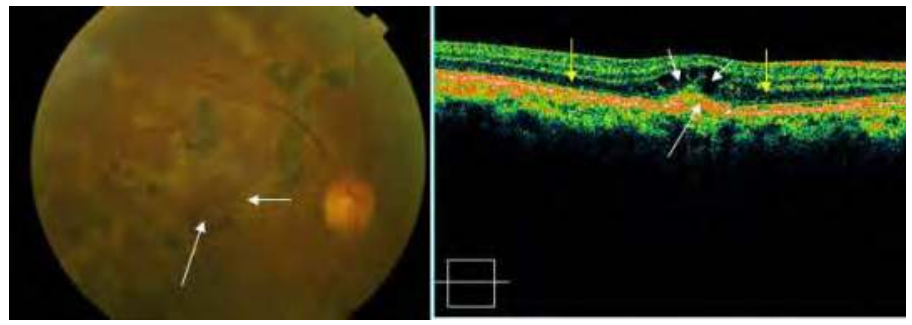

Fig. 11. Post-inflammatory CNVM (multifocal choroiditis) in right eye. Color fundus photo show subretinal exudates predominantly in macular area (small arrow), subfoveal grayish membrane (long arrow), and multiple hyperpigmented chorioretinal scars sequel to old inflammation. OCT shows hyperreflective CNVM scar (long white arrow) after PDT and four injections of ranibizumab. Note associated cystoid retinal fluid with septa (small white arrows), and a shallow neurosensory detachment (yellow arrows).
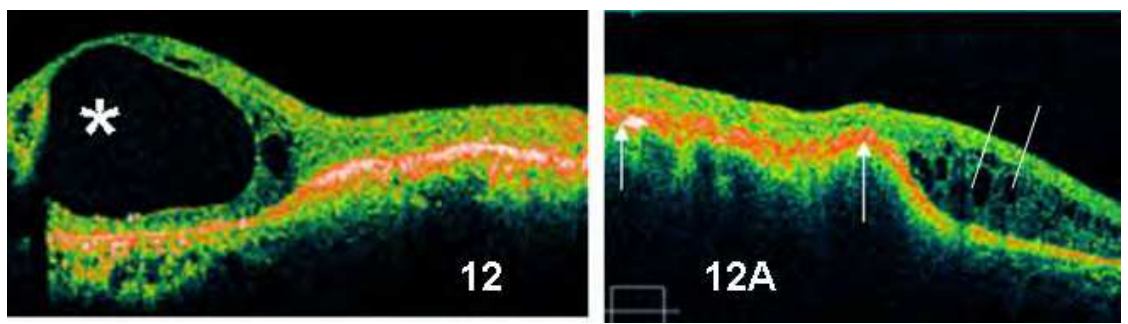

Fig. 12. OCT image showing a large cystic elevation of retina (asterisk). 12A: multiple intraretinal cystoid spaces (straight lines) with altered contour of the hyperreflective thickened retinal pigment epithelium (between arrows). 

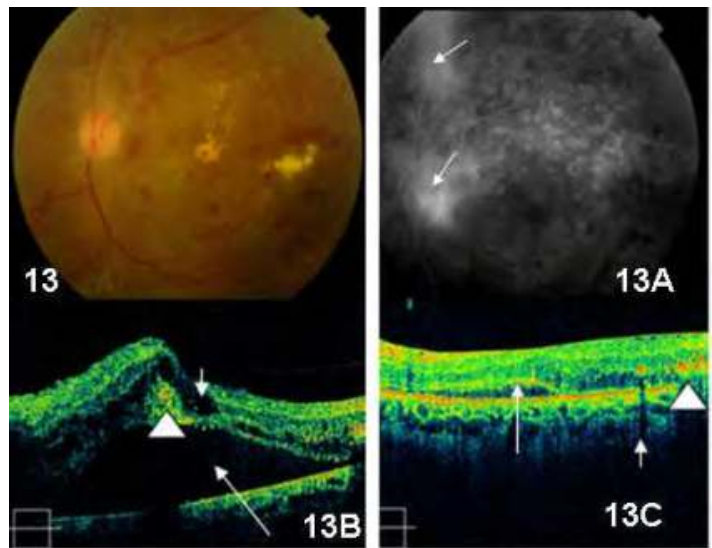

Fig. 13. Diabetic retinopathy in a 31 year old type 1 diabetes patient. Color fundus photo of left eye shows hemorrhages, exudates and retinal edema, mainly within temporal arcades. 13A: FA shows leakage (white arrows) suggestive of active proliferative diabetic retinopathy. 13B: OCT scan shows intraretinal edema (short arrow), subretinal fluid (long arrow) and hard exudates (arrowhead). Central retinal thickness (CRT) measured 470 microns). Fluid is represented by dark, optically empty spaces. Patient received intravitreal injection triamcinolone and laser. 13C: Right side OCT image: Eight weeks later there was improvement in macular edema (CRT 375 microns), with minimal residual edema and a small collection of subfoveal fluid (arrow). Hyperreflective exudates can be seen on right side of the scan (arrowhead). Also note the shadow effect of hard exudate (short arrow).

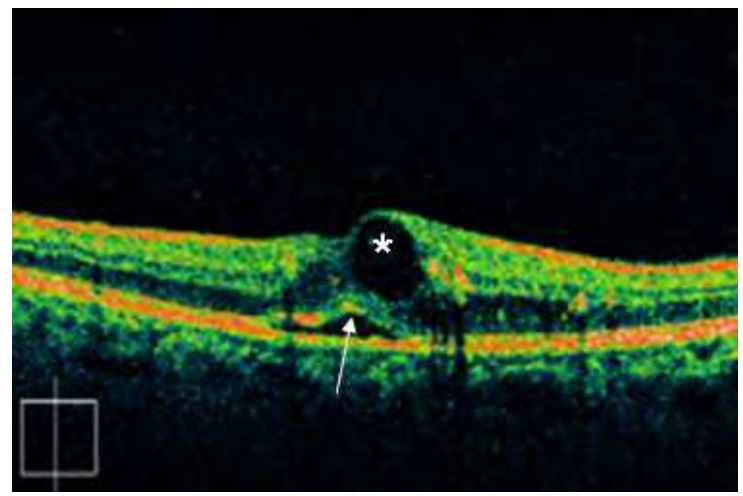

Fig. 14. A 56 year old male with type 1 diabetes mellitus. OCT shows retinal edema with an intra retinal cyst (asterisk). There is a small collection of subfoveal fluid (white arrow).

\subsection{OCT deformations of the retina: common causes}

- Concavity (myopia).

- Convexity (RPE detachment, subretinal cysts, subretinal tumors). It is not possible to image the entire tumor due to limitations on scanning depth (maximum $2 \mathrm{~mm}$ ).

- Disappearance of foveal depression, example clinically significant macular edema. 


\section{Clinical applications of optical coherence tomography in vitreo-retinal disorders (Gallemore et al., 2000; Stalmans et al., 1999)}

\subsection{Intraretinal fluid collections}

These include focal or diffuse edema, cystoid edema, cysts, microcysts and impending macular holes. OCT provides "analytical technique" serial scans which are helpful in quantifying the amount of intraretinal and or subretinal fluid.

\section{Retinal edema Figure 14.}

The primary cause of retinal thickening is edema. One of the major achievements of OCT has been quantitative assessment of this edema in terms of measuring retinal thickness and volume, evaluate progression of the pathologic process, and monitor surgical or nonsurgical intervention (Kang et al., 2004; McDonald et al., 1994). Retinal edema may present in following forms, individually or in combination.

Focal or diffuse edema: Common causes of diffuse macular edema include diabetic retinopathy, central retinal venous occlusion, branch retinal venous occlusion, arterial occlusion, hypertensive retinopathy, pre-eclampsia, eclampsia, uveitis, retinitis pigmentosa and retraction of internal limiting membrane. Initially there may be no or few visible changes. OCT may show reduced reflectivity and increased retinal thickness. As the edema progresses, OCT scan reveals spongy retina.

\section{Cystoid macular edema (CME): Figure 15}

There is intraretinal fluid collection in well defined retinal spaces (outer plexiform layer). The rosette or petalloid appearance is due to anatomical layout of the outer plexiform layer and the vertical Müller fibers. Common causes of CME include diabetic retinopathy, ARMD, venous occlusions, pars planitis, Uveitis, pseudophakos, Irvine-Gass syndrome, Birdshot retinopathy and retinitis pigmentosa. OCT usually shows diffuse cystic spaces in the outer nuclear layer of central macula, and increased retinal thickness which is maximally concentric on the fovea (Mavrofrides et al., 2004).
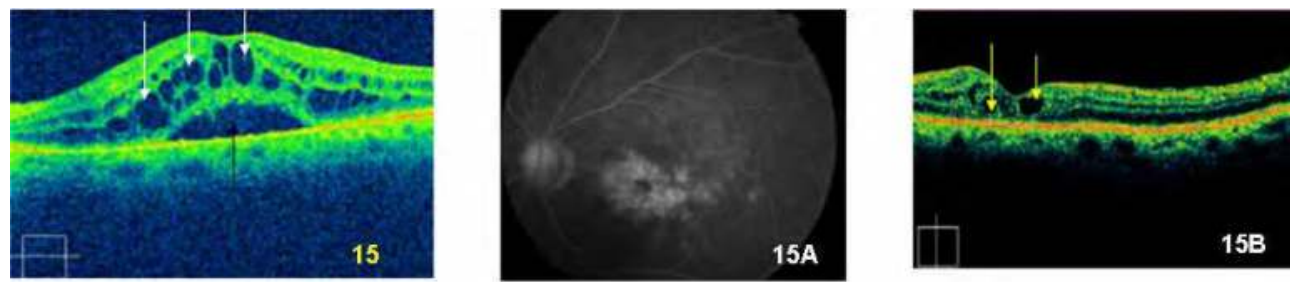

Fig. 15. Post-operative chronic cystoid macular edema. Left (15): OCT image shows multiple; optically empty cystoid spaces (white arrows) with intact septa and subfoveal fluid (black arrow). Pre-treatment central retinal thickness measured 738 microns. Note there are no underlying shadows. Middle (15A): FA shows classical cystoid macular edema. Right (15B): She received intravitreal triamcinolone, and one year later her retinal thickness measured 339 microns with few persisting cystoid spaces (yellow arrows). The subfoveal fluid has disappeared. 
Serous retinal detachment: It occurs sequel to chronic edema. The cysts loose their walls and merge together forming single or multiple pools of fluid within retinal layers (Figure 16) or between retinal pigment epithelium (RPE) and the sensory retina (Villate et al., 2004).

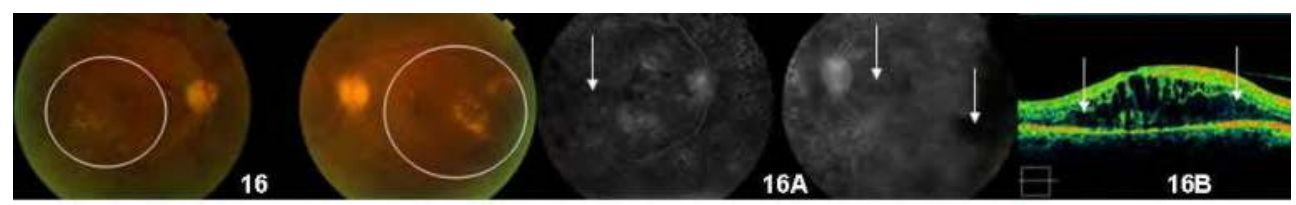

Fig. 16. Bilateral proliferative diabetic retinopathy in a 43 year old male. Color fundus photos have been taken during resolving vitreous hemorrhage, showing exudates and macular edema (encircled areas). 16A: FA shows prior laser marks and bilateral nonperfusion areas (white arrows). 16B: OCT scan highlighted merging of intraretinal fluid cysts (arrows) with some of the septa in the process of breaking down (between arrows) causing localized detachment of the neurosensory retina. OCT findings were much more informative than could be seen biomicroscopically.

\subsection{Subretinal fluid collections}

Serous retinal detachment: It's classical example is central serous chorioretinopathy (CSCR). Serous fluid with or without subretinal precipitates causes elevation of the sensory retina. Biomicroscopically it resembles a transparent bubble, FA shows slow filling of the dye while OCT reveals an optically empty space with or without cells or exudates (AlMujaini et al., 2008). Common causes of CSCR include pregnancy (Figure 17), subretinal neovascularization, optic disc colobomas, diabetic retinopathy, venous occlusions and choroiditis.

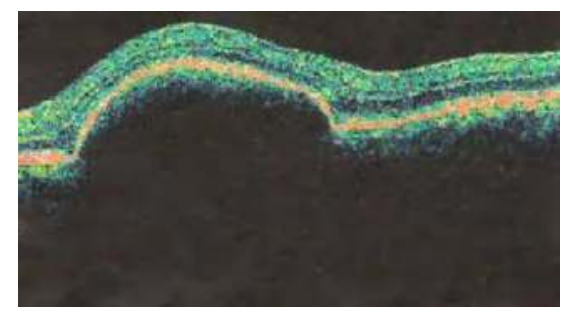

Fig. 17. Central serous chorioretinopathy with sub-retinal pigment epithelial fluid in a pregnant patient. 


\section{Retinal pigment epithelial detachment}
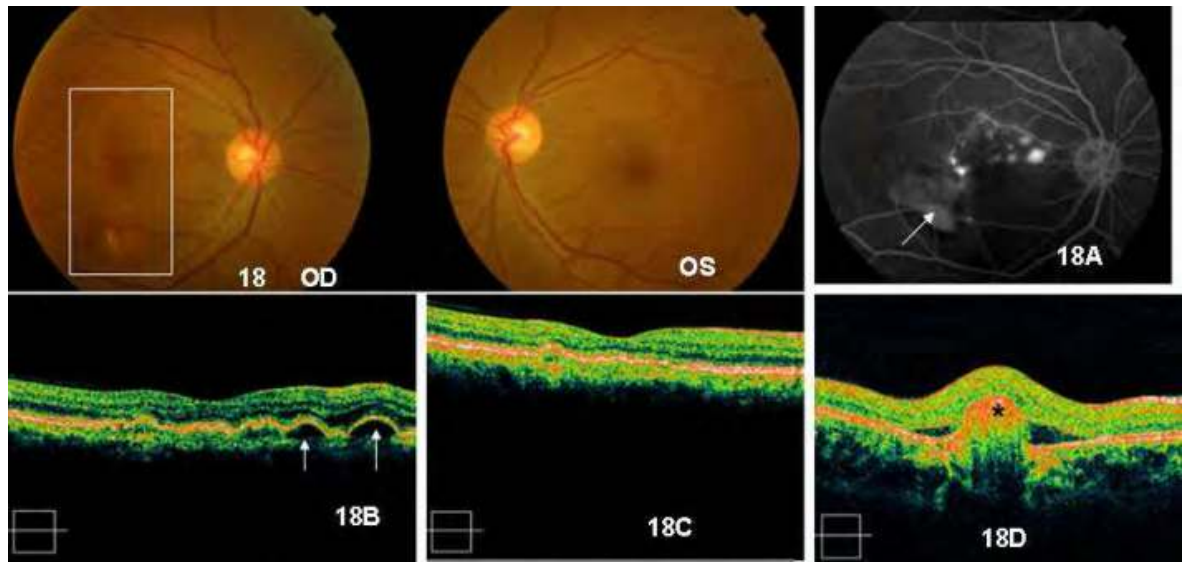

Fig. 18. Color fundus photos: OD: Retinal pigment epithelial detachment following PDT for ICG proved polypoidal choroidal vasculopathy (box). OS: Normal for comparison. 18A: FA shows multiple hyperfluorescent spots in late phase corresponding to RPE detachments/ polypoidal choroidal vasculopathy, and a well defined stained scar (arrow) infero-temporal to the fovea. 18B: OCT reveals dome shaped RPE detachments with collection of fluid under them (arrows). Patient was treated with intravitreal anti-VEGF therapy. 18C: Same patient as in 18B. OCT image shows resolution of the pathology after anti-VEGF treatment. 18D: OCT of an another 19 year old female with idiopathic CNVM scar and Pigment epithelial detachment (black asterisk).

It occurs due to leaking serous fluid from the choriocapillaries in the sub-RPE space or collection of blood under RPE causing its separation and elevation from the Bruchs membrane. OCT scans show a classical dome-shaped detachment of the RPE with intact contour in early stages (Figure 18). Differentiating features of OCT in various types of RPE detachments facilitate the clinical diagnosis (Table 3 ).

\begin{tabular}{|l|l|l|}
\hline Serous RPED & Inflammatory RPED Hemorrhagic RPED \\
\hline $\begin{array}{l}\text { Optically clear space with } \\
\text { reflective choriocapillaries }\end{array}$ & $\begin{array}{l}\text { Sub-RPE cells or } \\
\text { precipitates like fibrin. } \\
\text { Subdued choriocapillaries }\end{array}$ & $\begin{array}{l}\text { Shadow effect that prevents } \\
\text { choriocapillaries from being } \\
\text { seen. }\end{array}$ \\
\hline
\end{tabular}

Table 3. Differentiating features of pigment epithelial detachments. (RPED-retinal pigment epithelial detachment).

Common causes of RPE detachment include CSCR, ARMD with or without sub-retinal neovascularization, melanomas and other choroidal tumors (Hee et al., 1996).

\section{Role of OCT in CSCR}

- $\quad$ Presence and extent of subretinal fluid and PED.

- Quantitative monitoring of subretinal fluid. 
- Differentiation between CSCR and occult CNVM.

- Localization of leakage points which usually appear as PEDs (Robertson et al., 1986; Cardillo et al., 2003).

OCT in serous retinal detachment with RPE detachment: (Mavrofrides et al., 2004; Ting et al., 2002). Such detachments usually follow chronic diffuse retinal pigment epitheliopathy with optically empty contents. The detached neural retina forms shallow angle with the RPE while RPE detachment itself forms steep angles. (Figure 19).
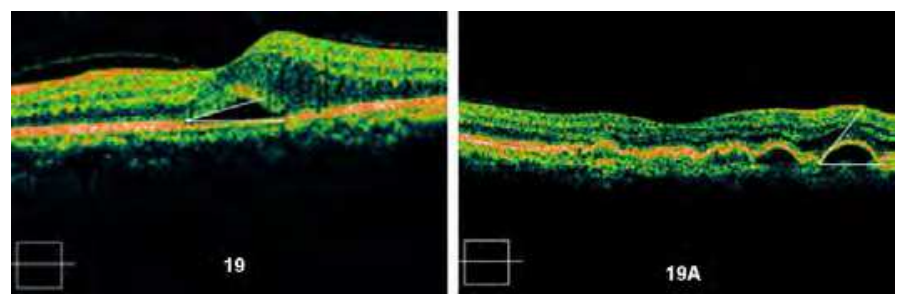

Fig. 19. The detached neurosensory retina forms shallow angle with the RPE. 19A: RPE detachment itself forms a steeper angle.

The RPE may be thickened and disrupted due to CNV. The small serous retinal detachments indicate that CNVM is active.

\subsection{Epiretinal membrane (ERM) / Macular pucker (cellophane maculopathy)}

Epiretinal membranes are glial proliferations on the vitreo-retinal interface. OCT does not have an impressive record of detecting ERMs; only $42 \%$ of eyes with such membranes were detected with this technique (Mavrofrides et al., 2005; Mori et al., 2004). However, other studies label OCT as an ideal instrument for detecting such membranes (Suzuki et al., 2003; Massin et al., 2000). This is due to the fact that both nerve fiber layer and epiretinal membrane are hypereflective, and the blending may sometimes make it difficult to differentiate the two. However, newer high-resolution OCT scans may show much improvement over this deficiency.

Clinical features / associations of ERMs include:

- Altered vascular architecture.

- Macular edema.

- May evolve into macular pseudoholes.

- Visual distortion and decreased vision.

- $\quad$ FA may show macular leakage.

Common causes of ERMs are vascular, uveitis, trauma and idiopathic. OCT scans reveal irregular retinal profile with small folds of the surface and changes in the contour of the foveal depression. Strongly adherent membranes that exert traction on the retina cause increase in retinal thickness, loss of foveal depression and retinal edema. The membrane may either elevate the retina or get itself detached from the retina. OCT enables evaluation of the density, thickness and location of such membranes. In mild cases OCT may only show increase in reflectivity along the internal retinal surface with no changes in internal limiting membrane (ILM) or intra-retinal reflectivity Figure 20). 


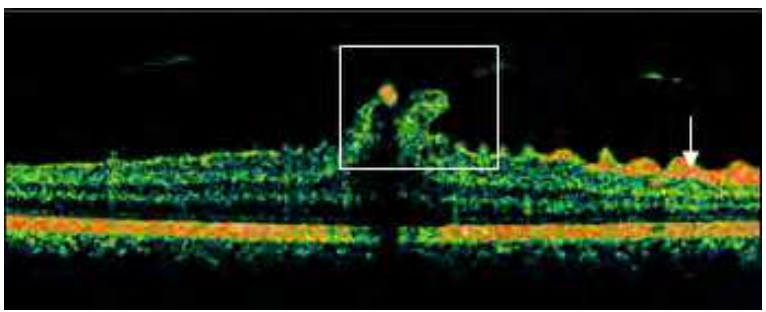

Fig. 20. Hypereflective ERM (white arrow) producing wrinkling of the retinal surface. There is associated vitreomacular traction (box). This patient had history of trauma with a football. Clinically it looked like a pseudohole which was confirmed by OCT.

Epiretinal membranes are best seen by OCT when there is some gap between the membrane and the inner retinal tissue. Conversely any epiretinal membrane that is tightly adherent to the retinal tissue may not be detected by OCT. Epiretinal membranes may induce schisis in the outer retinal layers, producing hyporeflective areas on OCT scanning. Such areas of schisis or edema may not be noticed by FA.

\subsection{Vitreomacular traction (Figures 10, 20 and 21)}

Clinical features of VMT: (Gallemore et al., 2000; Voo et al., 2004).

- Distortion of the macular contour.

- Antero-posterior and tangential tractional forces applied to the macula.

- Intraretinal edema with or without subretinal fluid.

Many cases of VMT are clinically undetectable; OCT is extremely valuable in such situations.

OCT features of VMT: Preretinal membranes may be thin or get thickened due to fibroglial proliferation and show hyperreflectivity. Such preretinal membranes correspond to detached posterior hyaloid membrane. The traction by the membrane to the retina induces deformations of the retinal surface (Figures 20 and 21).
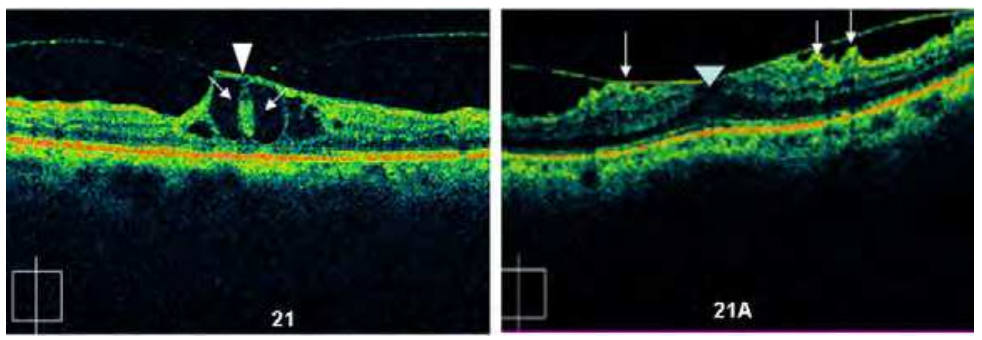

Fig. 21. An OCT image of a 51 year old diabetic and hypertensive patient having a constant vitreo-macular traction (arrowhead) causing cystoid macular edema (arrows). 21A: Vitreomacular traction: OCT of a 63 year old male shows a band in the vitreal cavity with adhesions at multiple points along the internal retinal surface (white arrows). There is increased retinal thickness, reduced intraretinal reflectivity due to edema. Note the lifted edges of the macula around the distorted foveal zone (pseudohole-arrowhead). 


\subsection{OCT in rhegmatogenous detachment}

The scan shows elevation of neural retina with extensive subretinal fluid. (Ip et al., 1999). It also documents the status of retinal detachment at baseline, while following up retinal anatomy after surgery.

\subsection{OCT in exudative retinal detachment}

- To document the presence, degree and extent of subretinal fluid (Villate et al., 2004).

- More accurate assessment of the level of retinal infiltrates and sub-RPE lesions.

- Detects macular edema in patients with chronic uveitis where hazy media may prevent clinical examination to find the cause of reduced vision (Antcliff et al., 2002; Markomichelakis et al., 2004).

\subsection{Macular pseudoholes and lamellar holes}

Pseudoholes occur in presence of epiretinal membranes with central defects. They overlay the fovea and may be ophthalmoscopically visible as true holes.

OCT features: (Figure 22-all features may not be displayed in a single scan).

- Homogenous increase in foveal and perifoveal retinal thickness.

- Diffuse reduction in intraretinal reflectivity due to edema.

- Increased perifoveal thickness leads to increase in apparent physiological foveal depression giving a false impression of a partial thickness macular hole, so called a pseudohole. This is a common feature with ERMs.

- In partial thickness or lamellar macular hole, OCT shows presence of residual retinal tissue at the base of the hole (above the RPE).

Macular hole: A macular hole is mostly age-related, common in females in the sixth or seventh decade. It results from centrifugal displacement of the photoreceptors from a central defect in the foveola. It should be noted that it is uncommon to have subretinal fluid in macular holes, when present, it is minimal. On the other hand macular holes are more often associated with intraretinal fluid accumulation and vitreofoveal traction (usually Gass stages 2 and 3) which give a curled-up appearance to the edges of the hole. OCT gives a sequence of documentation in ascertaining such changes in the genesis of a macular hole (Hee et al., 1995; Gaudric et al., 1999). Common causes of macular holes include idiopathic, trauma, high myopia, vascular causes (DR, venous occlusions, and hypertensive retinopathy) and subretinal neovascularization.

OCT and clinical features in macular holes: Table 4 and Figure 22 (not all features may be seen in a single scan).

- Complete absence of foveal retinal reflectivity. No residual retinal tissue.

- Thickened retinal margins around the hole with reduced intraretinal reflectivity.

- Perilesional cystoid edema, appearing as small cavities.

- Increased reflectivity of the inner retinal surface around the macular hole may represent posterior vitreous detachment (PVD-Figure 23), commonly seen as perifoveal vitreous separation which may be subclinical or not clinically visible (Roth et al., 1971; Sidd et al., 1982). 
- A hyperreflective band or a spot may be seen in front of the macula, which represents foveal pseudooperculum. (Pseudooperculum means separation of vitreous from fovea).

- Confirmation of successful surgical closure (Jumper et al., 2000; Sato et al., 2003).

- In partial or unsuccessful surgeries, OCT evaluates the retinal anatomy to find reason for poor visual outcome (Hee et al., 1995; Hikichi et al., 1995).

Often biomicroscopy and FA may not be conclusive in differentiating "ERMs associated pseudomacular holes" from true macular holes. OCT readily differentiates such lesions by depicting presence or absence of retinal tissue under the holes respectively.
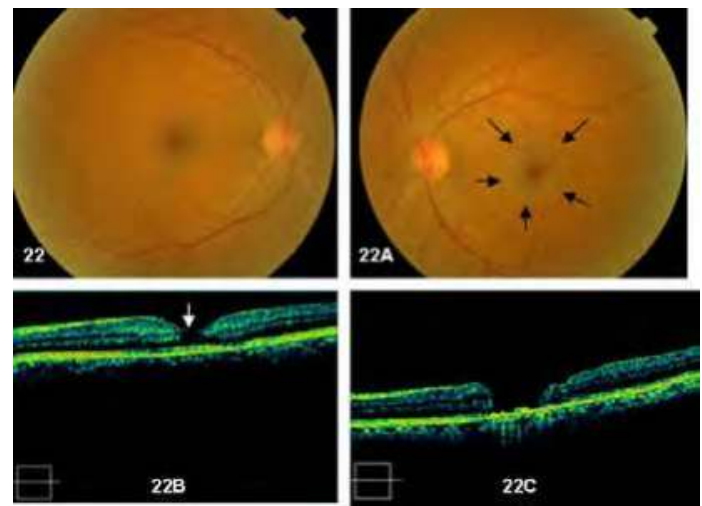

Fig. 22. Upper left: Fundus photo of normal right eye (for comparison). Upper right: (22A) Fundus photo of left eye showing a grayish white epiretinal membrane with a pseudohole appearance (within arrows). Lower left (22B): OCT image displaying an impending macular hole. A thin rim of intact tissue can be seen (white arrow). Lower right: (22C): OCT image of a non-responding full thickness macular hole of a long duration. See figure 1 for comparison with a normal macular-foveal retinal tissue morphology.

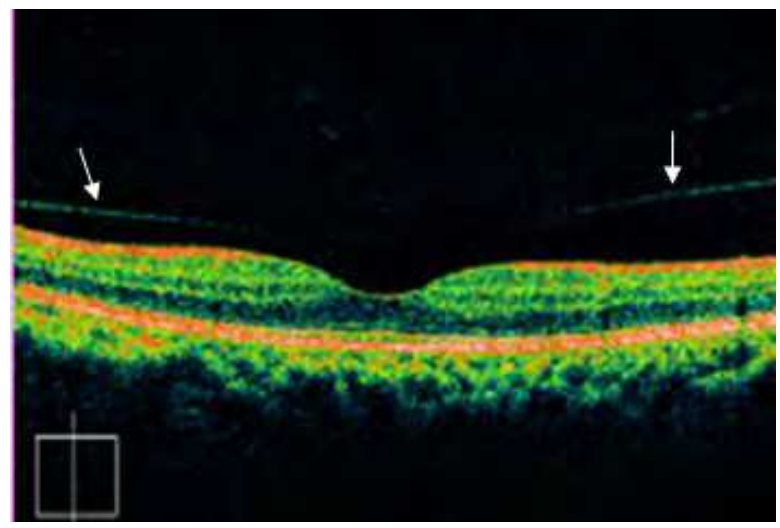

Fig. 23. Posterior vitreous detachments (arrows).

Stage-wise OCT features of genesis of macular holes: Gass classification; (Gass, 1995; Ip et al., 2002; Ullrich et al., 2002; Kasuga et al., 2000). 


\begin{tabular}{|c|c|c|}
\hline STAGE & CLINICAL FEATURES & OCT FEATURES \\
\hline $1 \mathrm{~A}$ & $\begin{array}{l}\text { Foveolar detachment } \\
\text { Foveal detachment }\end{array}$ & $\begin{array}{l}\text { Perifoveal separation of the } \\
\text { posterior hyaloid. Vitreous } \\
\text { attached to the fovea. }\end{array}$ \\
\hline $\begin{array}{l}2 \mathrm{~A} \\
2 \mathrm{~B}\end{array}$ & $\begin{array}{l}\text { Full thickness-Eccentric } \\
\text { Full thickness-central }\end{array}$ & $\begin{array}{l}\text { Small, full thickness retinal } \\
\text { defect or rupture of the roof } \\
\text { of the pseudocyst. }\end{array}$ \\
\hline $\begin{array}{l}3 \mathrm{~A} \\
3 \mathrm{~B}\end{array}$ & $\begin{array}{l}\text { Hole with operculum } \\
\text { Hole without operculum }\end{array}$ & $\begin{array}{l}\text { Full thickness retinal defect. } \\
\text { Adjacent neurosensory } \\
\text { detachment. } \\
\text { Intraretinal edema. } \\
\text { Epiretinal membrane. }\end{array}$ \\
\hline 4 & $\begin{array}{l}\text { Hole with posterior } \\
\text { vitreous separation }\end{array}$ & $\begin{array}{l}\text { Full thickness retinal defect. } \\
\text { Adjacent neurosensory } \\
\text { detachment. } \\
\text { Intraretinal edema. } \\
\text { Epiretinal membrane. }\end{array}$ \\
\hline
\end{tabular}

Table 4. Oct and macular hole staging.

As a rule impending macular holes have no pseudooperculum; partial thickness macular holes with ERM do have a pseudooperculum.

\begin{tabular}{|l|l|l|}
\hline Pseudooperculum & Operculum & Weiss' ring \\
\hline $\begin{array}{l}\text { Separation of vitreous from } \\
\text { fovea. }\end{array}$ & $\begin{array}{l}\text { Separation of roof of the } \\
\text { pseudocyst from the foveal } \\
\text { margin. }\end{array}$ & $\begin{array}{l}\text { Separation of vitreous } \\
\text { from the optic disc. }\end{array}$ \\
\hline
\end{tabular}

Table 5. Features of macular hole-related attachments.

\subsection{Retinoschisis (Figure 10)}

Definition: It is the separation or splitting of the neurosensory retina into an inner (vitreous) and outer (choroidal) layer with severing of neurons and complete loss of visual function in the affected area. In typical retinoschisis the split is in the outer plexiform layer, and in reticular retinoschisis, which is less common, splitting occurs at the level of nerve fiber layer. Retinoschisis may be degenerative, myopic, juvenile or idiopathic. Presence of vitreoretinal traction is an important pathogenic factor in its initiation. In X-linked retinoschisis, OCT reveals wide hyperreflective space with vertical palisades and splitting of the retina into a thinner outer layer and thicker inner layer (Eriksson et al., 2004).

\subsection{OCT in diabetic retinopathy (Cruz-Villegas et al., 2004; Schaudig et al., 2000)}

About three decades ago FA and laser photocoagulation improved our knowledge about pathogenesis and benefits of treatment in patients with DR. Since 2002 OCT has given a tremendous boost to the understanding of DR and its complications. This non-invasive technique has revolutionized the evaluation, treatment and prognosis of DR. 


\subsubsection{Nonproliferative diabetic retinopathy (NPDR) and diabetic macular edema}

Though OCT retinal thickness maps can be used to direct laser therapy, and sometimes may be better than biomicroscopy alone, one must be cautious not to proceed with laser photocoagulation in diabetic macular edema (DME) based solely on OCT findings. Ischemic retina may appear thinner on OCT. It is proper to include clinical examination and FA to guide treatment line in DR. Macular traction is an important association in DME which does not respond to laser therapy or intravitreal steroids (Pendergast et al., 2000). Such eyes have taut posterior hyaloid and show diffuse leakage on FA. OCT is very useful in recognizing this condition with following findings: Figure 24

- Diffuse cystic retinal thickening.

- Flat foveal contour.

- $\quad$ Thickened, hyperreflective vitreoretinal surface (Kaiser et al., 2001).

OCT enables the following analysis in DR:

- As an aid in finding the cause of visual impairment.

- Location and extent of retinal edema as a whole and within retinal layers.

- Indications and extent of photocoagulation therapy.

- Monitoring the effectiveness of laser, intravitreal or surgical therapy.
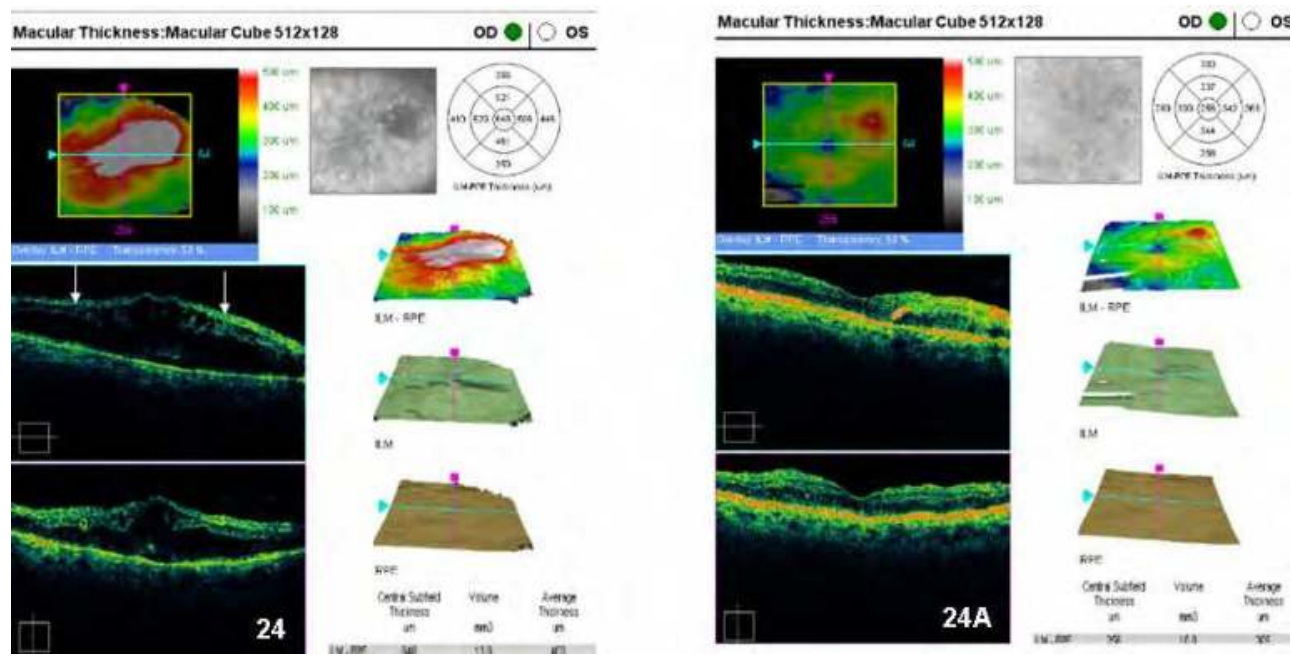

Fig. 24. Severe NPDR: Left image: Right eye of a sixty year old male with diabetic macular edema (before injection bevacizumab). Note the multiple intraretinal cystoid spaces, increasing the central retinal thickness to 648 microns. Right image (24A) belongs to same patient after intravitreal injection of bevacizumab $(1.25 \mathrm{mg})$ showing marked reduction in retinal edema (258 microns). Note the difference in color coded maps of retinal thickness as well. OCT has been valuable in following up this patient. 


\subsubsection{OCT appearance in common pathophysiologic lesions in DR}

- Cotton-wool spots: as hyperreflective nodular or elongated lesions in nerve fiber layer, often casting a shadow on posterior layers. (Figure 4)

- Hard exudates: (Figures 6). Appear as hyperreflective formations in deeper retinal layers. Common causes include DR, hypertensive retinopathy, Coats disease, telangiectasias and radiation retinopathy.

- $\quad$ Retinal hemorrhages: hyperreflective scans with shadows on posterior layers.

- Fibrous tissue: Appears as a hyperreflective area with deformation of macular outline. (Figure 7)

- Retinal edema: (Figures 3, 12,13,14) seen in OCT scans as thickened and hyporeflective, spongy retina. The edema is located by retinal mapping and quantified through measurement of retinal thickness and volume. OCT permits better localization of edema than can be done with FA. The external plexiform layer displays the greatest amount of edema. The spongy retina detected by OCT is thought to represent altered Müller cells. Over years, microcavities merge to form pseudocysts which are depicted clearly in OCT scans (Figure 15). Fully developed CME can involve full thickness of the retina with disappearance of retinal tissue, coalescence of the cavities, subsequently leading to a true serous neurosensory retinal detachment. OCT in such eyes reveals an optically clear cavity between elevated retina and RPE (Figure 25). One of the real supremacy of OCT in the field of CME from different causes has been to monitor the effectiveness of intravitreal therapeutic drugs in terms of retinal thickness and retinal volume (Figures $5,13,15,18,24$, and 25).
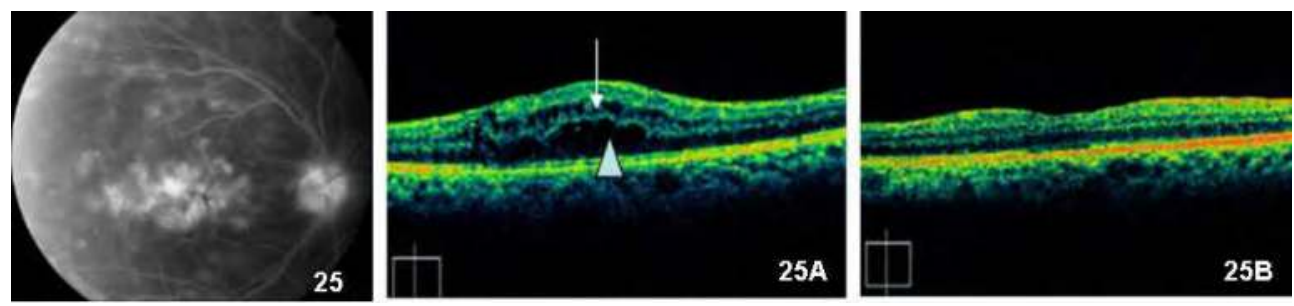

Fig. 25. Postoperative endophthalmitis: FA shows petalloid cystoid macular edema. 25A: OCT image shows persistent cystoid macular edema (white arrow) with central subfoveal thickness of 530 microns and shallow neurosensory detachment (arrowhead). She was given intravitreal triamcinolone. 25B: Repeat OCT after 2 weeks showed marked reduction in macular edema (central subfoveal thickness 230 microns). Patient continued to be free of macular edema six months after intravitreal injection.

\subsubsection{OCT and proliferative diabetic retinopathy (PDR) Figure 26}

Proliferative diabetic retinopathy occurs commonly in young individuals where newly formed vessels appear at the margin of the ischemic area. Common causes of retinal neovascularization include DR, CRVO, Eale's disease, vasculitis, pars planitis and sickle cell anemia. Uncommon causes include leukemias and multiple myelomas. The newly formed abnormal blood vessels are thin and fine and are picked up in OCT scans only when glial tissue is present with vessels. 

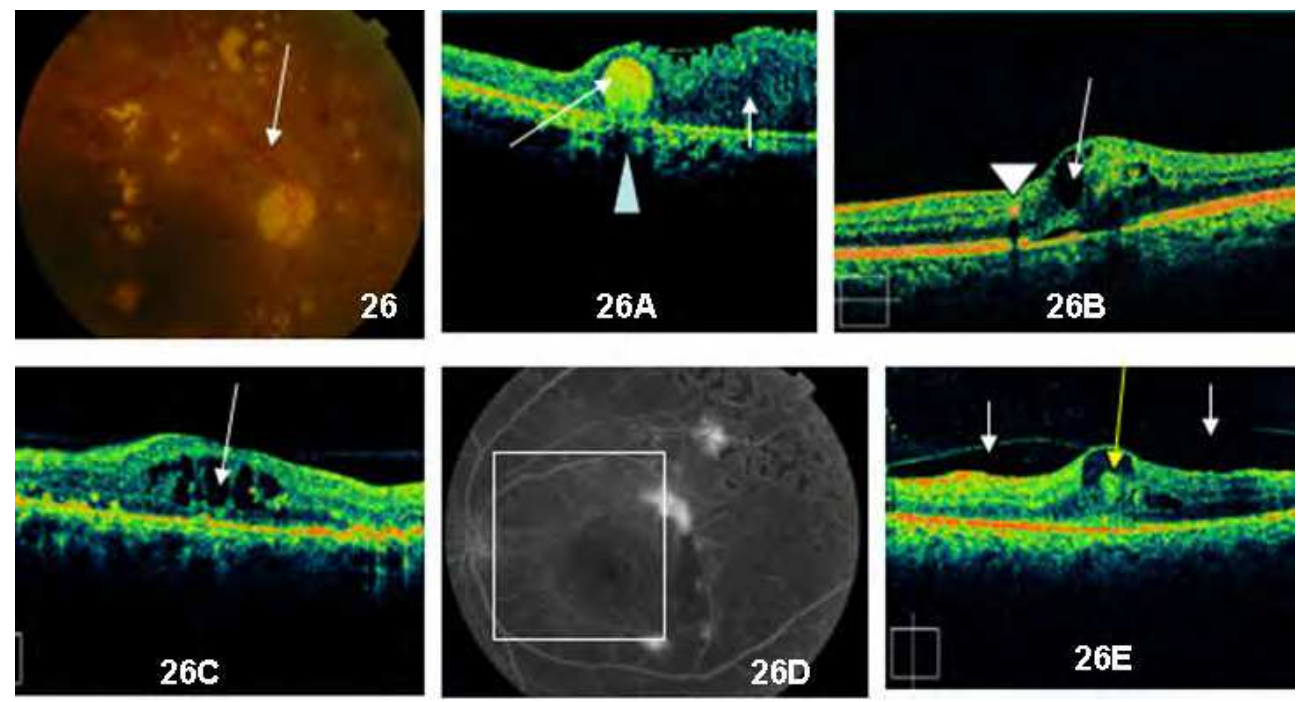

Fig. 26. Proliferative diabetic retinopathy: Color fundus photo shows extensive hard exudates and glial tissue proliferation (arrow). 26A: OCT image of the same patient depicts partially hyperreflective round exudate (long white arrow) amidst macular edema (short arrow). Note the underlying shadow cast by overlying exudate (arrowhead). 26B Another patient with cystoid macular edema (arrow) and intraretinal exudate (arrowhead).

Bottom row: A 42 year old male diabetic patient with bilateral proliferative diabetic retinopathy. 26C: OCT image shows clinically significant macular edema (Central subfoveal thickness 619 microns). Note the optically empty cysts (arrow) do not caste any underlying shadows. 26D: FA shows ischemic retinopathy (white rectangle) with areas of non-perfusion and leaking NVE. 26E: Large intraretinal cyst (yellow arrow) with vitreo-macular traction (white arrows).

\subsubsection{OCT in traction with or without retinal detachment}

OCT typically shows points of traction on the retina causing its elevation (FIGURES 10, 20, 21), intraretinal fluid accumulation causing retinal thickening. (Figure 21) and Subretinal fluid collection (Figure 20). If OCT rules out traction as a cause of vision loss, macular ischemia should be a strong reason then.

\section{Drusen}

Drusen are round, yellowish colloidal bodies associated with Bruch's membrane. They may be single (large single drusen also called vitelliform) or multiple (geographic), hard or soft, later variety being more damaging to the retinal pigment epithelium-photoreceptor layer.

OCT findings in drusen (Mavrofrides et al., 2004)

Highly refractive irregular, convex excrescences in the form of thickenings or deformities of the RPE-Bruch's membrane complex (external band), leading to its irregular or undulating 
outline (Figure 8). Geographic atrophy of RPE elicits increased reflectivity from underlying exposed choroid. Retinal thinning due to focal or diffuse retinal atrophy may ensue. Drusen unlike hard exudates do not cast any underlying shadows in OCT scans.

\section{Age Related Macular Degeneration (ARMD)}

Drusen are the earliest findings in ARMD. The disease has dry (atrophic) form in 80 percent of cases and wet (exudative) form in 20 percent of cases. OCT is particularly useful in evaluating different modes of therapies, namely photodynamic therapy (PDT), intra-vitreal antiangiogenic therapies and surgical treatment (Giovannini et al., 1999, 2000; Rogers et al., 2002).

\subsection{Dry (atrophic) ARMD}

Macular region shows clusters of drusen and progressive atrophy of RPE, photoreceptors and choriocapillaries. OCT scans show reduced retinal thickness, increased RPE reflectivity due to reduced light attenuation by atrophic retinal tissue (Mavrofrides et al., 2004)

\subsection{Wet (exudative) ARMD (Ting et al., 2002)}

The typical components of exudative ARMD include serous elevation of RPE and neurosensory retina, hemorrhage under RPE and Subretinal hemorrhage. Figures 27, 28

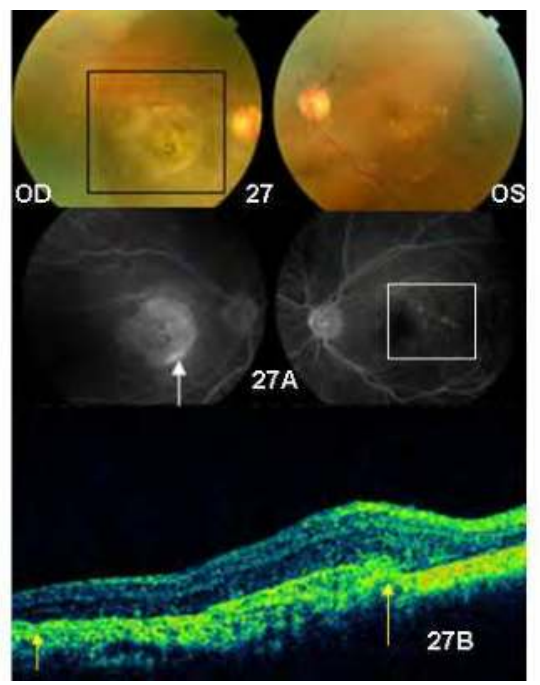

Fig. 27. Age related macular degeneration with scarred CNVM (right eye) in a 62 year old male. Color fundus photo of right eye (OD) shows a large grayish elevated macular lesion with drusen infero-temporal to the macula (square). Left eye (OS) color fundus photo shows multiple drusen inferior and temporal to macula. 27A: FA shows stained scarred CNV with doubtful activity inferiorly (arrow) in right eye and stained small drusen bodies in the left eye (white square). 27B: OCT scan right eye showed minimal reflectivity (between yellow arrows). Patient was earlier treated with intravitreal ranibizumab and bevacizumab injections. The vision remained unchanged in the treated eye. 

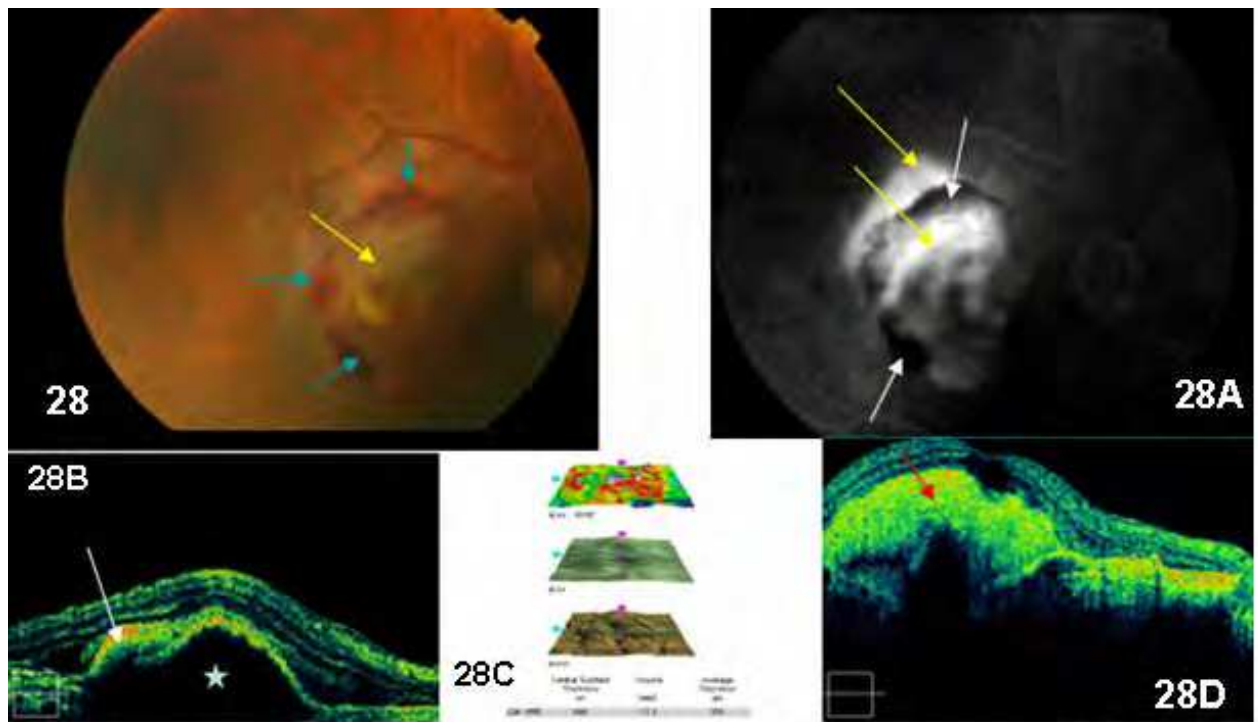

\section{6-SEPT-2009}

$28 \mathrm{C}$

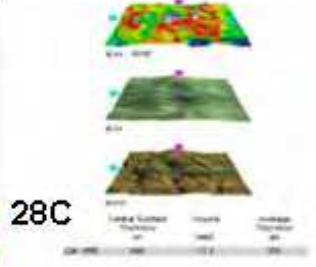

20 APR 2010

Fig. 28. Advanced age-related macular degeneration in an 89 year old male (right eye). Color fundus photo shows a large subfoveal hemorrhage (blue arrows) and a large disciform scar (yellow arrow). 28A: FA shows blocked fluorescence (white arrows) due to hemorrhage and hyperfluorescent areas (yellow arrows) defining stained fibrous tissue. 28B: OCT image shows black, optically empty area corresponding to presence of fluid (star) and hyperreflective scar (white arrow). 28C: Note the irregularity in the color maps. Patient received three injections of intravitreal bevacizumab. 28D: OCT after 8 months (April 2010): The CNVM scar remained unchanged (red arrow). Patient did not show any visual improvement. Treatment was abandoned.

\subsection{OCT in ARMD Figures 27 and 28}

It provides vital information about different presentations of ARMD in different stages, more common and more important being the following:

- $\quad$ Serous RD.

- Hemorrhagic RD.

- Retinal edema.

- Cystoid edema.

- RPE detachment.

- Neovascular membranes.

- Subretinal fibrosis.

- As an adjunct to FA/Indocyanine angiography.

Fluorescein Angiography may not be equivocal in defining intraretinal, subretinal or subRPE fluid; OCT scans all these components vividly and identifies location and level of such fluid, besides giving clue to the contents of the fluid (blood, serous fluid, pigment, and 
fibrosis). Unlike FA, OCT yields quantitative data about retinal thickness, volume and size of the CNV.

\section{Classic choroidal neovascular membranes - OCT findings (Figure 10)}

Neovascular lesions appear as highly refractile, fusiform areas beneath the retina. Secondary exudation may be seen as intraretinal or subretinal fluid. Intraretinal edema may be mild or diffuse and cystic. OCT is highly sensitive in picking up even small amounts of subretinal fluid (seen as non-reflective space) between outer retina and highly refractile external band (RPE-choriocapillaries complex). No technique other than OCT can monitor the quantitative response of different methods of treatment in CNV (Giovannini et al., 1999, 2000; Rogers et al., 2002).

Occult choroidal neovascular membranes: Usually located sub-RPE and may lead to fibrovascular PED. FA shows mottled hyperfluorescence. OCT reveals PED with irregular external band and variable subretinal or intraretinal fluid.

\section{Pigment epithelial detachment (PED)}

Usually accompanies occult CNV lesions. Other common causes include idiopathic, CSCR (Figure 17) and ocular inflammations. Classical PEDs have continuous, highly reflective bands on both sides of the lesion. Any discontinuity favors an RPE tear or presence of an overlying inflammatory exudate, blood or fibrin which block the incident OCT beam of light.

OCT and serous PED: Figure 18 The OCT findings include a dome shaped optically clear space between RPE and choriocapillaries. Detached RPE forms a steep angle with underlying choriocapillaries. The contents of the serous cavity may be clear or contain cells or fibrin. The detachments may be single or multiple. Sometimes they may merge and form a bubble; however, this does not obstruct the view of the underlying choroid.

OCT and hemorrhagic PED: The source of blood is a neovascular membrane. The RPE detachment, like serous detachment, forms a steep angle with choriocapillaries but, unlike serous detachment, obscures the underlying choriocapillaries and all other posterior layers due to inability of OCT light beam to penetrate blood. The anterior face of the hemorrhage elicits a very high optical reflectivity.

\section{RPE tears}

(Gelisken et al., 2001; Pece et al., 2001; Srivastava et al., 2002). RPE tear is a serious complication of ARMD and PDT.

Common causes:

- $\quad$ Serous and hemorrhagic PED.

- Following laser treatment like PDT.

- Long standing sub-RPE fluid collection due to active CNV.

OCT changes in RPE tear include: 
- $\quad$ Thickening (secondary to retraction of RPE) and folding of RPE layer.

- $\quad$ Blood under RPE. This may induce dense shadow on posterior layers.

- An area of irregular, thick hyperreflective outer band with intense backscattering. This area corresponds to where RPE has retracted and underlying choriocapillaries have been bared.

OCT is valuable in aiding clinical diagnoses in many other RPE lesions like hamartomas and hyperplasias (Lopez \& Guerrero, 2006; Shukla et al., 2005).

\section{Choroidal Neovascular Membrane (CNVM-Figure 10)}

FA is invaluable in detecting both classic and occult CNV. OCT reveals CNVM as a hyperreflective area in front of or in contact with, or slightly separated from an irregular RPE. When active, OCT invariably shows retinal edema or neurosensory RD. With involuntary regression of CNVM, OCT images become less evident. In Occult CNVM the new vessels predominantly lie in sub-RPE space. Such occult neovascular membranes are difficult to identify clinically or sometimes even with FA. OCT clearly depicts an irregular, thickened, disrupted and fragmented RPE in such cases. There may be associated retinal cystoid edema and neurosensory RD opposite the membrane (Figure 10). Common causes of CNVM include exudative from of ARMD, myopia (usually with axial length of more than $26 \mathrm{~mm})$, idiopathic neovascularization in young patients, idiopathic polypoidal vasculopathy, retinal angiomatosis, traumatic choroidal ruptures, post-photocoagulation therapy, angioid streaks, choroiditis and histoplasmosis.

\section{Idiopathic polypoidal vasculopathy (IPV) or polypoidal neovascular membranes (Figure 18)}

This disorder is a variant of ARMD, found in patients aged fifty years and above (Yannuzzi et al., 1997). FA / ICG reveals dilated choroidal vessels with ectasias or aneurysms, often in clusters. There may be associated serous or hemorrhagic detachment of the retina and RPE.

It may masquerade as CSCR. ICG differentiates the two conditions (Yannuzzi et al., 2000).

Laser treatment yields good results. OCT shows cup-shaped elevation of RPE and serous (no underlying shadow) or hemorrhagic (with shadow effect) detachments of the retina and or RPE.

\section{Retinal angiomatous proliferans}

Clinical features:

- Intraretinal neovascularization.

- Intraretinal hemorrhage with or without PED.

- Cystic retinal edema.

OCT features:

- Intraretinal cystic edema.

- PED. 
- Hyperreflective intraretinal neovascular complex (Yannuzzi et al., 2001; Zacks \& Johnson, 2004).

- Serous subretinal or sub-RPE fluid.

\section{Idiopathic juxtafoveal retinal telangiectasia}

Clinical features:

- Common retinal vascular disorder affecting young to middle aged males.

- Telangiectatic vessels have predilection for temporal macula.

- Macular edema as reason for reduced vision.

- Telangiectasis appears often in small, right angled venular groups which are seen better in high magnification.

- FA shows leakage mostly temporal to the macula.

- OCT shows normal foveal contour and horizontally oriented oblong, small, inner retinal cysts.

\section{Disciform scars / subretinal fibrosis (Figure 7, 28, 29)}

Scars develop as a sequel to regression of subretinal hemorrhages and prolonged retinal edema. They are composed of fibrovascular tissue and hyperplastic RPE. There usual location being between altered Bruch's membrane and the retina which is often elevated. They may mask the end stage of untreated CNVMs. On FA the scars may appear as areas of hyperfluorescence with late staining. This may be confused with persisting leakage from a CNVM lesion. The decision whether or not to re-treat such a lesion with PDT is facilitated by OCT imaging. In dry variety (common) there is pronounced destruction of almost all retinal layers, while in rarer exudative variant there may be serous or hemorrhagic exudation from leaking CNVM, causing retinal elevation. OCT findings include an area of nodular hyperreflectivity with deformation or irregularity of adjacent retina and RPE. In exudative type, OCT scans show diffuse or cystoid retinal edema and RPE detachments. Absence of intraretinal thickening or subretinal fluid usually indicates non-active CNV complex within the scar tissue complex. OCT greatly facilitates differentiation between active $\mathrm{CNV}$ complexes from subretinal fibrosis. Occasionally chronic end-stage, burnt out CNV may be associated with overlying intra-retinal cysts-this could be an associated chronic inflammation rather an active $\mathrm{CNV}$.

\section{Post-therapeutic assessment by OCT (Figures $5,13,15,18,24,25$ )}

OCT provides an accurate outcome of the effect of pharmacological or surgical interventions like PDT, transpupillary thermotherapy, vitreoretinal surgery, anti-VEGF therapy, intravitreal steroid therapy and therapeutic Intravitreal implants (Rogers et al., 2002).

\section{Retinal venous occlusions: Figure 5}

In Branch retinal venous occlusion, technician should be asked to arrange vertical scan through the foveal center. This shows classical vertical disparity between normal retina and thick cystic retina. 


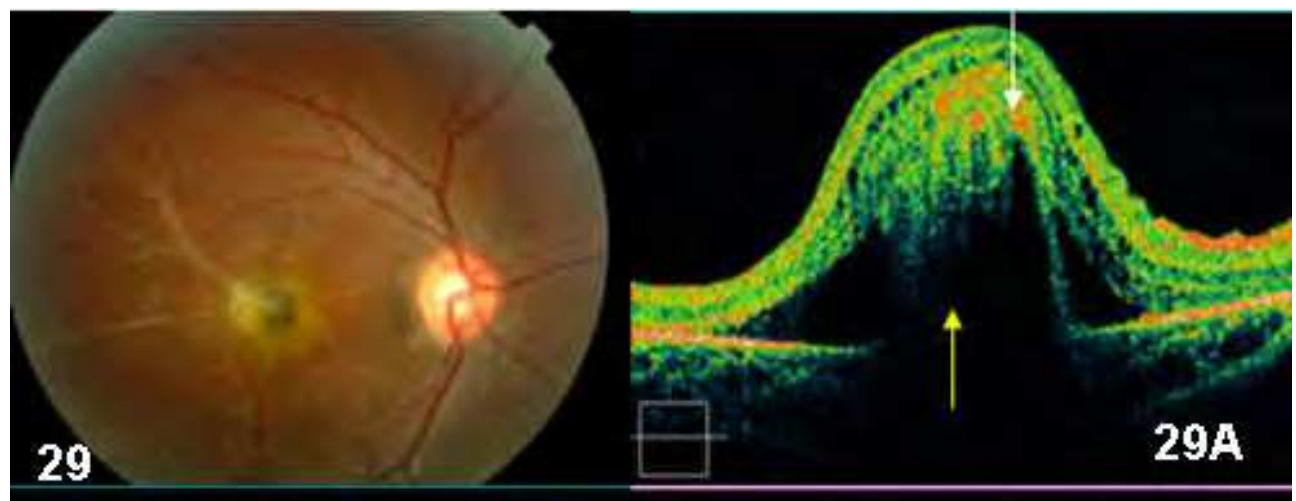

\section{$29 B$}

Fig. 29. A 15 year old male patient with Best disease. Color fundus photo shows central fibrosis following resolved CNVM with RPE hyperplasia. 29A: OCT right eye shows hyperreflective scar (white arrow) within markedly elevated macula with subretinal fluid (yellow arrow). 29B: OCT left eye shows a hyperreflective dome shaped lesion (white arrow) which was clinically compatible with a circumscribed scrambled egg lesion. Note the absence of subretinal fluid in left eye. 29C: (another patient): CNVM after LASIK: OCT image of a 31 year old female who developed CNVM after LASIK procedure. OCT shows a post-CNVM hyperreflective macular scar (white arrow) following three PDT therapies and intravitreal bevacizumab.

\section{OCT findings:}

- Diffuse intraretinal cystic collections causing retinal thickening. Such cysts are evenly distributed throughout the macula (Ip et al., 2003; Lerche et al., 2001; Sekiryu et al., 2000).

- Subretinal fluid.

There are certain rarer conditions that show significant intraretinal cystic spaces in OCT scans, but do not leak on FA. These include X-linked juvenile retinoschisis, Goldman-Favrevitreoretinal degeneration, nicotinic acid maculopathy, docetaxel (anti-neoplastic drug) toxicity and few variants of vitreomacular traction (Spirn et al., 2003; Teitelbaum \& Tresley 2003). 


\section{Optic disc pits}

Recently it has been proposed that fluid from the vitrous enters through the pit and then traverses between the inner and outer layers of the retina producing a retinal schisis. OCT has confirmed such an inner retinal schisis preceding the outer retinal layer detachment (Krivoy et al., 1996; Lincoff \& Kreissig, 1998). It was found from OCT scans that the RNFL thickness is reduced in the quadrant corresponding to the optic nerve pit (Myer et al., 2003).

\section{Retinitis pigmentosa}

OCT displays the associations of this disease like epiretinal membrane and cystoid macular edema. (Figure 2) The outer nuclear layer thickness may appear normal in the foveal region, but becomes abnormally thin in the macular periphery. UHR-OCT may show progressive thinning of the outer and inner segments of the photoreceptors outside of the foveal region (Ko et al., 2005).

\section{OCT in rarer posterior segment lesions}

Melanomas: OCT does not detect the internal characteristics of melanocytic tumors (Espinoza et al., 2004). It identifies the associated features like subretinal fluid (Muscat et al., 2004), intraretinal cystic changes and schisis-like splitting of the overlying neurosensory retina.

Choroidal osteomas: OCT is not of much help in assisting the diagnosis, however, may help in confirming associated clinical features like overlying CNV, subretinal fluid, retinal edema or thinning and attenuation of the overlying RPE. Osteomas induce partial shadowing of the choroids (Fukasawa \& Lijima, 2002).

\section{Optical coherence tomography and its applications in glaucoma}

The RNFL represents a highly reflective band whose anterior limit begins at the vitreoretinal interface, and the posterior limit is detected on the basis of signal thresholding. OCT provides both qualitative and quantitative information regarding the optic nerve and the RNFL. The images in this chapter are based on Cirrus 3D HD domain, therefore, may differ from older versions of the OCT. The measurement of the RNFL thickness marks one of the most important applications of OCT in the field of ophthalmology. The authenticity of pathological specificity of OCT RNFL measurements correlates with histological measurements in primate and human studies, and this has been correlated with visual field changes as well (Chen et al., 2006). An OCT RNFL report generated by Cirrus-3D HD OCT in a normal person reads as following: Figure 30.

Section 1 and 1A: RNFL thickness maps for right eye and left eye respectively. The maps report thickness using GDx (glaucoma diagnostics) color pattern, where warm colors (reds, yellows) represent thicker areas and cool colors (blues and greens) represent thinner areas.

Section 2 and 2A: RNFL thickness deviation maps for right and left eyes respectively. These maps report statistical comparison against normal thickness range, overlaid on the fundus OCT image. These maps apply only yellow and red colors. The green color is not applied because it may obscure the anatomical details in the underlying OCT fundus image, as most 
of the superpixels would be green for normal patients. Any region that is not red or yellow means it falls within normal limits. One can have a gross clue of the cup-disc ratio and position of the vessels in the cup.
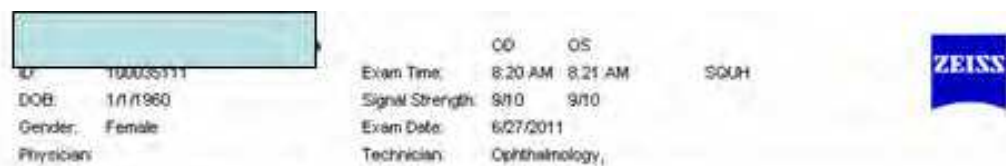

mrtican

Techician Cohehainology,

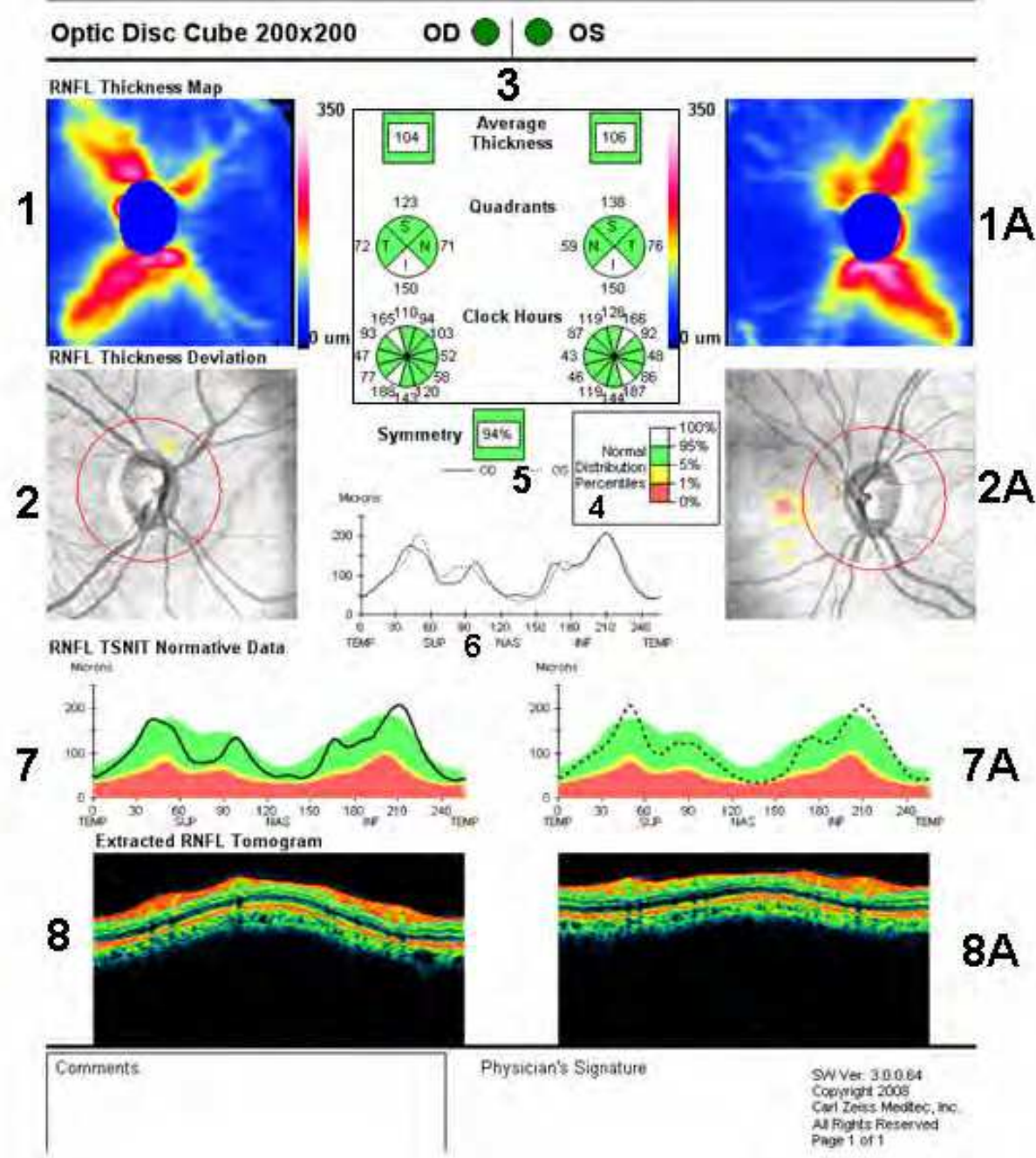

Fig. 30. See text. 
Section 3: Displays average RNFL thickness along the whole calculation circle (squares in the print out, as well as quadrant and clock hour measurements). These measures are represented in pseudocolor (means these colors are not same as the RNFL in vivo) coded programs by comparing the measured RNFL thickness to age-matched data in the normative database of the OCT machine. Green and white colors indicate normal RNFLT (white color means thickest). Note that red color in the map (section 1) denotes more thickness of the RNFL contrary to red color of boxes or quadrants or clock hours in section 2 where red indicates reduced average thickness of the RNFL.

Sections 4: The RNFL normative database uses a white-green-yellow-red color code to indicate the normal distribution percentiles. The color code applies to the quadrant, clock hour, graphs, and to the right (OD) and left (OS) columns. The percentiles apply as follows (among same-age individuals in the normal population):

Red represents thinnest $1 \%$ of measurements and is considered outside normal limits.

Yellow represents thinnest $5 \%$ of measurements and is considered suspect.

Green represents $90 \%$ of measurements and is considered normal.

White area represents thickest $5 \%$ of all measurements.

Note: Ophthalmologists must exercise clinical judgment while interpreting the normative data because one out of twenty normal eyes (5\%) will fall below green.

Section 5: Symmetry: Indicates the extent of symmetry of distribution of RNFL thickness in TSNIT (temporal-superior-nasal-inferior-temporal) quadrants between two eyes. The symmetry parameter is a correlation coefficient, converted to a percentage and does not have much applicability in patient management. One can ignore this parameter in clinical decisions.

Section 6: RNFL-TSNIT thickness graph: OU (Both eyes): This section plots RNFL thickness in $\mathrm{Y}$ axis (vertical) and retinal quadrants in $\mathrm{X}$ axis (horizontal). This normally has a "double hump" appearance owing to the thicker RNFL measurements in the superior and inferior quadrants compared with the nasal and temporal quadrants. This profile shows right and left eye RNFL thickness together, to enable comparison of symmetry in specific regions.

Section 7 and 7A: Separate RNFL-TSNIT normative data graph for right and left eyes respectively. The graph is superimposed against the color codes. If the graph dips into red color in any quadrant, the RNFL thickness in that quadrant is not normal (Figure 31 section 7 and $7 \mathrm{~A})$

Section 8 (OD) and 8A (OS): Extracted RNFL tomograms. Display the reflectivity of the RNFL. Not of much clinical significance in taking clinical decisions. Some models of OCT can display optic disc modules including parameters like cup-disc ratio (vertical and horizontal), neuroretinal rim area, disk area, cup area, cup volume, rim volume etc.

An OCT RNFL report generated by Cirrus-3D HD OCT in a patient with glaucoma is interpreted as following: Figure 31. 


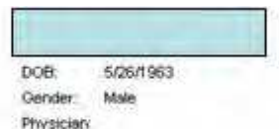

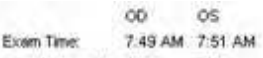

$$
\begin{aligned}
& \text { Shal Strength. } 8110 \text { 8no } \\
& \text { Exam Dutec 7r32011 }
\end{aligned}
$$$$
\text { Sout }
$$

\begin{tabular}{ll|l}
\hline Optic Disc Cube $200 \times 200$ & OD & OS \\
\hline
\end{tabular}

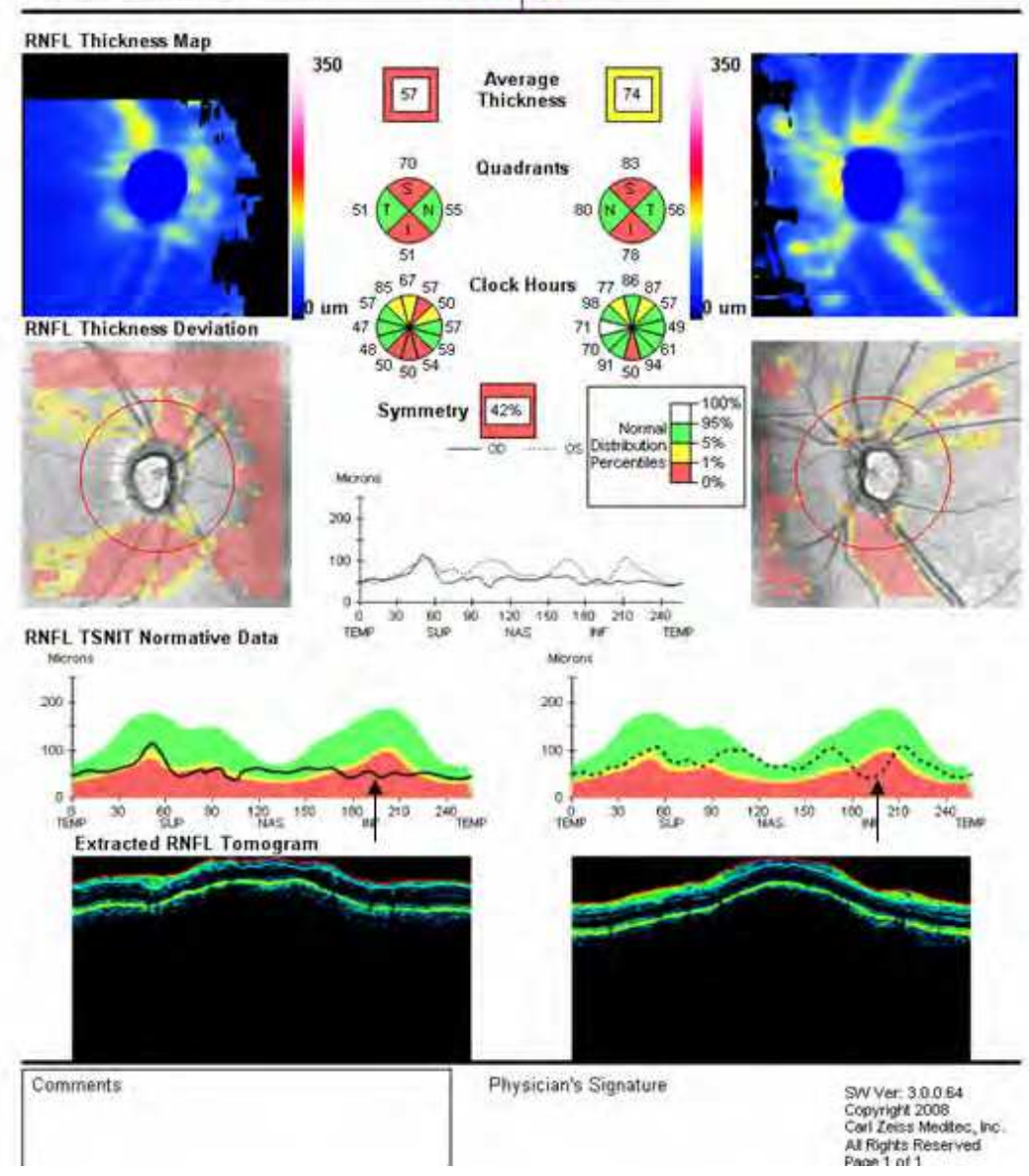

Fig. 31. Section 1: Note absence of red color code compared to normal OCT. This indicates thinning of RNFL. Section 2: There is a pink-red brush paint appearance (absent in normal OCT). This again indicates wedge shaped NFL defect. Section 3: The average RNFL thickness in the right (OD) eye is represented in red square, which indicates abnormal (reduced) NFL thickness (red denotes values $\leq 1 \%$ of what would be expected when compared with a reference population of the same age as the patient while the average RNFL thickness in the left (OS) eye is represented in yellow square, indicating a value which is borderline or suspect, or a subclinical involvement, or a normal variant (such patients need regular follow up). Section 4: Same interpretation as for normal scan. Section 5: An abnormal symmetry (red square) of RNFLT between two eyes. Note that symmetry square in normal OCT scan is green and healthy. Section 6: Absence of double-hump due to 
marked thinning and asymmetry of NFLT between two eyes. Section 7: Note the significant dipping of graph into red zone in both eyes (black arrows). This happens when there is advanced atrophy of nerve fibers (in this case due to glaucoma). Another important cause could be MS. Section 8: same interpretation as in normal OCT.

\section{OCT in systemic diseases}

The application of OCT has gone beyond the borders of ophthalmology. Ocular manifestations of systemic diseases are widely accepted as important clues to the diagnosis, treatment and follow up of such disorders. OCT has added a new dimension in this field. Few examples from hematological and neurological disorders have been cited in this chapter, but the list is much more (Figure 32).

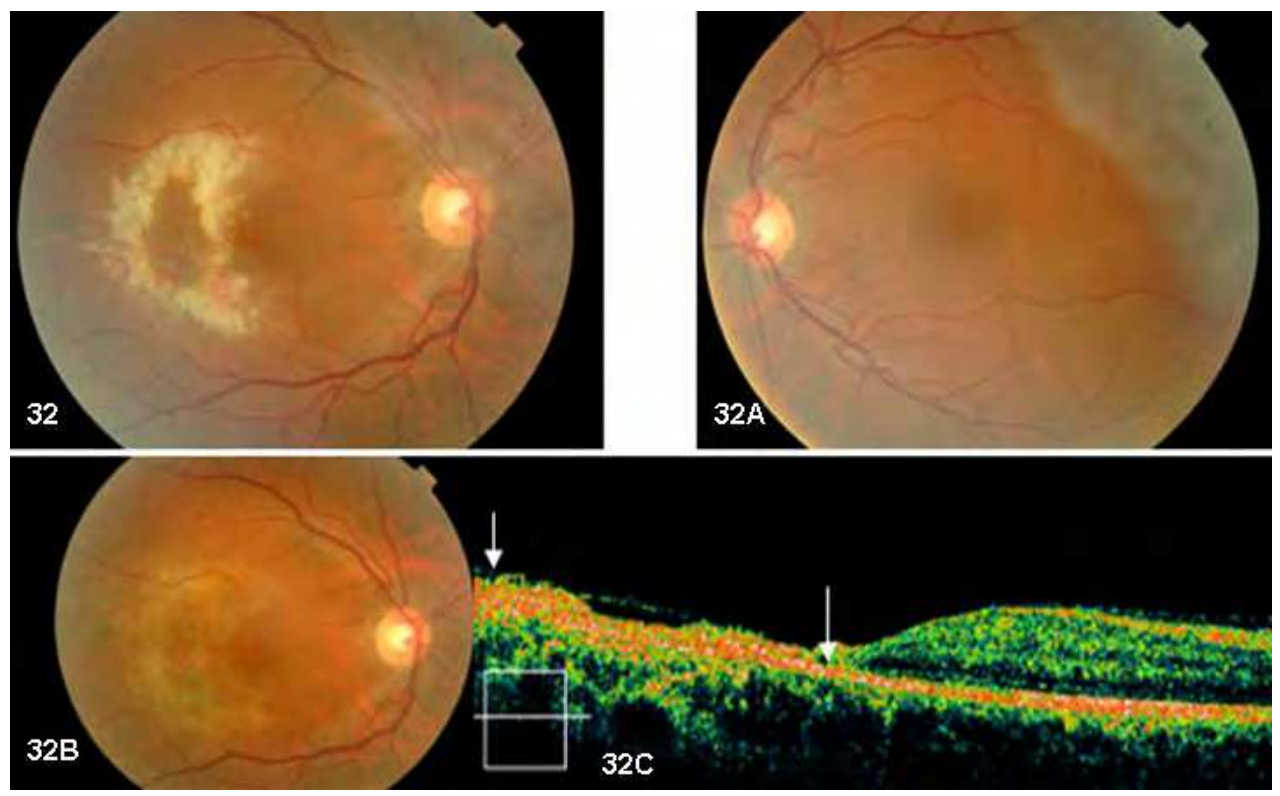

Fig. 32. OCT in systemic disease: A 45 year old male with acute lymphoid leukemia (ALL) complained of reduced vision $(6 / 60)$ in right eye. His associated ocular co-morbidity included cytomegalovirus retinitis in right eye. Figure 32: Fundus photo in June 2011 revealed paramacular ring shaped retinal opacification, with hemorrhages, which were attributed to leukemic cell infiltration and possible CMV retinitis. 32A: normal left eye for comparison. Patient received chemotherapy. 32B: After 5 weeks, fundus examination revealed marked resolution of retinal opacification, replaced by scarring. 32C: OCT in July 2011 showed marked retinal atrophy and a hyperreflective scar (between arrows-central subfield thickness 38 microns). Compare it to the normal retinal thickness nasal (right side of the scan) to the fovea.

OCT in multiple sclerosis (MS): The first study to report ocular OCT findings in MS patients was published by Parisi et al in 1999. Both academic and industrial scientists have been quick to realize the potential utility of OCT as a surrogate marker of axonal integrity in 
MS. As a result OCT research in MS has grown exponentially in recent years and it has become an undisputed corroborator into the design of ongoing clinical trials. The disability level in MS is best correlated with axonal damage, but axonal damage is poorly appreciated on MRI. The RNFL is composed primarily of unmyelinated axons that originate from the ganglion cells. In addition to providing an indication of axonal integrity through measurement of RNFL thickness, OCT provides evaluation of the outer macula which is felt to provide an estimate of neuronal integrity within the retina (Burkholder et al., 2009; Moura et al., 2007). OCT measurement of RNFL thickness reflects axonal integrity, while its measurement of total macular volume reflects retinal neuronal integrity. MRI does not provide insight into the process of subclinical optic neuropathy or the subsequent neurodegenerative sequelae that ensue in the retina as a result of optic neuropathy. Studies found that the thickness of RNFL was reduced in patients with MS, and it correlated with visual evoked potential P100 amplitude (a reflection of axonal integrity) than with P100 latency (a reflection of myelin integrity), supporting the notion that RNFL thinning in MS is attributed to axonal degeneration and this, in turn reflects the degree of brain atrophy (Gordon-Lipkin et al., 2007). OCT imaging following acute inflammatory optic neuritis has shown that approximately $75 \%$ of patients ultimately sustain 10-40 micron reduction in RNFL thickness in the affected eye within 3-6 months, indicating significant and rapid axonal degeneration secondary to demyelination. OCT has documented that RNFL thickness threshold of 75 microns, below which there is a reduction in visual function. This observation has been confirmed with automated perimetry testing (Costello et al., 2006).

Based on the correlating findings of OCT, it appears that individuals with progressive MS variants suffer greater RNFL thinning than those with relapsing-remitting variants (Pulicken et al., 2007). Pathological specificity of OCT RNFL measurements correlates with histological measurements in primate and human studies and yields good structurefunction correlation between RNFL thickness and low-contrast visual acuity (Fisher et al., 2006; Pulicken et al., 2007).

\section{Aberrant variations of OCT scan}

It may be due to retinal edema, denser media opacities and ERMs which may be located at a very short distance from the retinal surface. Such measurements complicate the interpretation and may not correspond to the reality. New versions of OCT may perform better in such situations.

\section{OCT in anterior segment imaging (Console et al., 2008; Devereux et al., 2000; Wang et al., 2010; Wu et al., 2011)}

Anterior segment imaging is a rapidly advancing concept in ophthalmology. New technologies offering non-contact cross-sectional imaging of the cornea and the anterior segment are now commercially available. These new modalities, based on rotating Scheimpflug imaging and anterior segment OCT; supplement the already established imaging techniques like slit corneal topography and ultrasound biomicroscopy. One of such applications of anterior segment OCT is commercially available as Visante OCT. It uses the physical principle of low-coherence interferometry to generate images of the anterior segment. Anterior segment OCT uses a longer wavelength $(1310 \mathrm{~nm})$ that permits deeper 
penetration through the highly reflective tissues of the sclera and is minimally affected by corneal opacifications. The system provides anterior segment images up to $6 \mathrm{~mm}$ in depth and $16 \mathrm{~mm}$ in width. Therefore, this technology permits morphological and morphometric plus qualitative and quantitative analysis of the anterior segment. (Fishman GR et al., 2005; $\mathrm{Li} \mathrm{H}$ et al., 2007). One of the most valuable advantages of anterior segment OCT is its ability to produce a reliable representation of anterior chamber structures in presence of total loss of corneal transparency.

OCT is used in evaluating the anterior segment of the eye e.g. cornea, iris, anterior chamber and the central portion of the lens. It analyses the anterior chamber angle in patients with different angle configurations, particularly when gonioscopy is not possible due to different prevailing circumstances (Landoy-Kalev et al., 2007). This technique appears to be a promising tool in assessment of the anterior chamber angle configuration in various angle closure glaucomas as well as in glaucoma suspects, and those with ocular hypertension (Radhakrishan et al., 2007). OCT depicts changes induced by laser iridotomies, and can be used as a rapid screening tool for detection of occludable angles.

Visante OCT was approved by FDA in 2005 as a non-contact, high resolution tomographic and biomicroscopic device for in-vivo imaging and measurement of ocular structures in the anterior segment such as corneal and LASIK flap thickness. Fourier-domain OCT and Visante OCT (time-domain) have been studied in assessing corneal and trabecular-iris angle disorders, central corneal thickness, trabecular-iris angle, and angle-opening distance (Pekmezci et al.,2009; Wylegala et al., 2009). OCT devices with biomicroscopy provide images of the scleral spur, ciliary body, ciliary sulcus, anterior chamber depth, and even canal of Schlemm in some eyes. Such anatomical landmarks help in phakic intra-ocular lens implantation (Konstantopoulos et al., 2007).Though OCT has been utilized for imaging of trabeculectomy blebs (Singh et al., 2007), capsular block syndrome (Lau et al., 2007), residual Descemet's membrane after Descemet's stripping endothelial keratoplasty (Kymionis et al., 2007), as well as visualization of aqueous shunt position and patency (Sarodia et al., 2007), there is currently inadequate evidence to support its application in these indications. Anterior-segment OCT has imaged small hypopigmented tumors with complete penetration, however, cysts behind iris pigment epithelium, highly pigmented tumors, large tumors, and ciliary body could not be penetrated completely. In these situations, ultrasound biomicroscopy was undoubtedly superior to the OCT (Pavlin et al., 2009).

\section{Future strategy}

Adaptive optics in combination with SD-OCT is going to be a new high-definition, threedimensional retinal microstructural imaging technology in coming years. OCT derived pachymetry to capture focal thinning in keratoconus is being developed. Coming up are OCT-guided femtosecond laser capsulotomies in cataract surgeries where accuracy of the capsulotomy size, shape, and centration has been quantified in porcine and human eyes (Freidman et al., 2011).

\section{OCT in artificial vision}

This innovation provides qualitative and quantitative information about the retina-implant interface. It enables to follow epiretinal implants anatomically in both animal models and human patients (Panzan et al, 2004). 


\section{References}

Aguirre AD, Hsiung P, Ko TH, Hart I, Fujimoto JG, et al. (2003). High-resolution optical coherence microscopy for high speed, in vivo cellular imaging. Opt Lett, Vol. 28, No. 21, (Nov), pp. 2064-2066.

Al-Mujaini A, Wali U, Ganesh A, Montana C. (2008). Natural course of Central Serous Chrioretinopathy without subretinal exudates in Pregnanacy. Can J Ophthalmol, Vol. 43, No. 5, (Oct), pp. :588-90.

Antcliff RJ, Stanford MR, Chauhan DS, Graham EM, Spalton DJ, et al. (2002). Comparison between Optical coherence tomography and fundus fluorescein angiography for the detection of cystoid macular edema in patients with uveitis. Ophthalmology, Vol. 107, No. 3, (Mar), pp. 593-599.

Burkholder BM, Osborne B, Loguidice MJ, Bisker E, Frohman TC, et al. (2009). Macular volume determined by optical coherence tomography as a measure of neuronal loss in multiple sclerosis. Arch Neurol, Vol. 66, No. 11, (Nov), pp. 1366-1372.

Cardillo Piccolino F, Eandi CM, Ventre L, Longrais RC, Grignolo FM, et al. (2003). Photodynamic therapy for chronic central serous chorioretinopathy. Retina, Vol. 23, No. 6, (Dec), pp. 752-763.

Chen TC, Cense B, Miller JW, Rubin PA, Daschler DG, et al. (2006). Histologic correlation of in vivo optical coherence tomography images of the human retina. Am J Ophthalmol, Vol. 141, No. 6, (Jun), pp. 1165-1168.

Console JW, Sakata LM, Aung T, Friedman DS, He M. (2008). Quantitative analysis of anterior segment Optical coherence tomography images: the Zhongshan angle assessment program. Br J Ophthalmol, Vol. 92, No. 12, (Dec), pp. 1612-1616.

Costello F, Coupland S, Hodge W, Lorello GR, Koroluk J, et al. (2006). Quantifying axonal loss after optic neuritis with optical coherence tomography. Ann Neurol, Vol. 59, No. 6, (Jun), pp. 963-969.

Cruz-Villegas V, Flynn HW Jr. Diabetic retinopathy. In: Schuman JS, Puliafito CA,

Cruz-Villegas V, Puliafito CA, Fujimoto JG. (2004). Retinal vascular diseases. In: Schuman JS, Puliafito CA, Fujimoto JG, eds. Optical coherence tomography of ocular diseases. Thorofare, NJ: SLACK, Inc.; 103-156.

Devereux JG, Foster PJ, Baasanhu J, Uranchimeg D, Lee PS, et al. (2000). Anterior chamber depth measurement as a screening tool for primary angle closure glaucoma in the East Asian population. Arch Ophthalmol, Vol. 118, No. 2, (Feb), pp. 257-263.

Drexler W, Morgner U, Ghanta RK, Kärtner FX, Schuman JS, Fujimoto JG. (2001). Ultrahigh resolution ophthalmic optical coherence tomography. Nat Med, Vol. 7, No. 4, (Apr), pp. :502-507.

Drexler W, Morgner U, Kärtner FX, Pitris C, Boppart SA, et al. (1999). In vivo ultrahigh resolution Optical coherence tomography. Optics Lett, Vol. 24, No. 17, (Sep), pp. 1221-1223.

Eriksson U, Larsson E, Holmstrom G. (2004). optical coherence tomography in the diagnosis of juvenile X-linked retinoschisis. Acta Ophthalmol Scand, Vol. 82, No. 2, (Apr), pp. 218-23. 
Espinoza G, Rosenblatt B, Harbour JW. (2004). Optical coherence tomography in the evaluation of retinal changes associated with suspicious choroidal melanocytic tumors. Am J Ophthalmol, Vol. 137, No. 1, (Jan), pp. 90-95.

Fisher JB, Jacobs DA, Markowitz CE, Galetta SL, Volpe NJ, et al. (2006). Relation of visual function and retinal nerve fiber layer thickness in multiple sclerosis. Ophthalmology, Vol. 113, No. 2, (Feb), pp. 324-332.

Fishman GR, Pons ME, Seedor JA, Liebmann JM, Ritch R. (2005). Assessemnt of central corneal thickness using Optical coherence tomography. J Cataract Refract Surg, Vol. 31, No. 4, (), pp. 707-711.

Friedman NJ, Planker DV, Schuele G, Anderson D, Marcellino G, et al. (2011). Femtosecond laser capsulotomy. Journal of cataract and refractive surgery, Vol. 37, No. 7, (Jul), pp. 1189-1198.

Fujimoto JG, eds. Optical coherence tomography of ocular diseases. Thorofare, NJ: SLACK, Inc., 2004:157-214.

Fujimoto JG, Hee MR, Duang D et al. Principles of optical coherence tomography. In: Schuman JS, Puliafito CA, Fujimoto JG, eds. Optical coherence tomography of ocular diseases. Thorofare, NJ: SLACK; 2004: 3-20.

Fujimoto JG. (2003). Optical coherence tomography for ultrahigh resolution in vivo imaging. Nat Biotechnol, Vol. 21, No. 11, (Nov), pp. 1361-1367.

Fukasawa A, Lijima H. (2002). Optical coherence tomography of choroidal osteoma. Am J Ophthalmol, Vol. 133, No. 3, (Mar), pp. 419-421.

Gallemore RP, Jumper JM, McCuen BW 2nd , Jaffe GJ, Postel EA, Toth CA (2000). Diagnosis vitreoretinal adhesions in macular disease with optical coherence tomography. Retina, Vol. 20, No. 2, pp. 115-120.

Gass JD. (1995). Reappraisal of biomicroscopic classification of stages of development of a macular hole. Am J Ophthalmol, Vol. 119, No. 6, (Jun), pp. 752-759.

Gaudric A, Haouchine B, Massin P, Pacques M, Blain P, Erginay A. (1999). Macular hole formation: new data provided by optical coherence tomography. Arch Ophthalmol, Vol. 117, No. 6, (Jun), pp. 744-751.

Gelisken F, Inhoffen W, Partsch M, Schneider U, Kreissig I. (2001). Retinal pigment epithelial tear after photodynamic therapy for choroidal neovascularisation. Am J Ophthalmol, Vol. 131, No. 4, (Apr), pp. 518-520.

Giovannini A, Amato G, Mariotti C, Scassellati-Sforzolini B. (2000). Optical coherence tomography in the assessment of retinal pigment epithelial tear. Retina, Vol. 20, No. 1, pp. 37-40.

Giovannini A, Amato GP, Mariotti C, Scassellati-Sforzolini B. (1999). OCT imaging of choroidal neovascularisation and its role in the determination of patients' eligibility for surgery. Br. J Ophthalmol, Vol. 83, No. 4, (Apr), pp. 438-442.

Gordon-Lipkin E, Chodkowski B, Reich DS, Smith SA, Pulicken M, et al. (2007). Retinal nerve fiber layer is associated with brain atrophy in multiple sclerosis. Neurology, Vol. 69, No. 16, (Oct), pp. 1603-1609

Hee MR, Baumal CR, Puliafito CA, Duker JS, Reichel E, et al. (1996). Optical coherence tomography of age-related macular degeneration and choroidal neovascularisation. Ophthalmology, Vol. 103, No. 8, (Aug), pp. 1260-1270. 
Hee MR, Fujimoto JG, Ko T et al. Interpretation of the optical coherence tomography image. In: Schuman JS, Puliafito CA, Fujimoto JG, eds. Optical coherence tomography of ocular diseases. Thorofare, NJ: SLACK, Inc.; 2004:21-56.

Hee MR, Puliafito CA, Duker JS, Reichel E, Duker JS, et al. (1998). Topography of diabetic macular edema with optical coherence tomography. Ophthalmology, Vol. 105, No. 2, (Feb), pp. 360-370.

Hee MR, Puliafito CA, Wong C, Duker JS, Reichel E, et al. (1995). Optical coherence tomography of macular holes. Ophthalmology, Vol. 102, N0. 5, (May), pp. 748756.

Hee MR, Puliafito CA, Wong C, Duker JS, Reichel E, et al. (1995). Quantitative assessment of macular edema with optical coherence tomography. Arch Ophthalmol, Vol. 113, No. 8, (Aug), pp. 1019-1029.

Hikichi T, Yoshida A, Trempe CL. (1995). Course of vitreomacular traction syndrome. Am J Ophthalmol, Vol. 119, No. 1, (Jan), pp. 55-61.

Hoang QV, Linsenmeier A, Chung CK, Curcio CA. (2002). Photoreceptor inner segments in monkey and human retina: mitochondrial density, optics, and regional variation. Vis Neurosci, Vol. 19, No. 4, (Jul-Aug), pp. 395-407.

Hrynchak P, Simpson T. (2007). Optical coherence tomography: an introduction to the technique and its use. Optom Vis Sci, Vol. 77, No. 7, (Jul), pp. 347-356.

Huang D, Swanson EA, Lin CP, Schuman JS, Stinson WG, et al. (1991). Optical coherence tomography. Science, Vol. 254, No.5035, (Nov), pp.1178-1181.

Ip M, Garza-Karren C, Duker JS, Reichel E, Swartz JC, et al. (1999). Differentiation of degenerative retinoschisis from retinal detachment using optical coherence tomography. Ophthalmology, Vol. 106, No. 3, (Mar), pp. 600-605.

Ip M, Kahana A, Altaweel M. (2003). Treatment of central retinal vein occlusion with triamcinolone acetonide: an optical coherence tomography study. Semin Ophthalmol, Vol. 18, No. 2, (Jun), pp. 67-73.

Ip MS, Baker BJ, Duker JS, Reichel E, Baumal CR, et al. (2002). Anatomical outcomes of surgery for idiopathic macular hole as determined by optical coherence tomography. Arch Ophthalmol, Vol. 120, No. 1, (Jan) pp. 29-35.

Jumper JM, Gallemore RP, McCuen BW 2nd, Toth CA. (2000). Features of macular hole closure in the early postoperative period using optical coherence tomography. Retina, Vol. 20, No. 3, pp. 232-237.

Kaiser PK, Riemann CD, Sears JE, Lewis H. (2001). Macular traction detachment and diabetic macular edema associated with posterior hyaloidal traction. Am J Ophthalmol, Vol. 131, No. 1, (Jan), pp. 44-49.

Kang SW, Park CY, Ham DI. (2004). The correlation between fluorescein angiographic and optical coherence tomographic features in clinically significant diabetic macular edema. Am J Ophthalmol, Vol. 137, No. 2, (Feb), pp.313-322.

Kasuga Y, Arai J, Akimoto M, Yoshimura N. (2000). Optical coherence tomography to confirm early closure of macular holes. Am J Ophthalmol, Vol. 130, No. 5, (Nov), pp. $675-676$. 
Ko TH, Fujimoto JG, Schuman JS, Paunescu LA, Kowalevicz AM, et al. (2005). Comparison of ultrahigh-and standard resolution optical coherence tomography for imaging macular pathology. Ophthalmology, Vol. 112, No. 11, (Nov), pp. 1922-1935.

Konstantopoulos A, Hossain P, Anderson DF. (2007). Recent advances in ophthalmic anterior segment imaging: A new era for ophthalmic diagnosis. Br J Ophthalmol, Vol. 91, No. 4, (Apr), pp. 551-577.

Krivoy D, Gentile R, Liebmann JM, Stegman Z, Rosen R, et al. (1996). Imaging congenital optic disc pits and associated maculopathy using optic coherence tomography. Arch Ophthalmol, Vol. 114, No. 2, (Feb), pp. 165-170.

Kymionis GD, Suh LH, Dubovy SR, Yoo SH. (2007). Diagnosis of residual Descemet's membrane after Descemet's stripping endothelial keratoplasty with anterior segment Optical coherence tomography. J Cataract Refract Surg, Vol. 33, No. 7, (Jul), pp. 1322-1324.

Landoy-Kalev M, Day AC, Cordeiro MF, Migdal C. (2007). Optical coherence tomography in anterior segment imaging. Acta Ophthalmol Scand, Vol. 85, No.4, (Jun), pp. 427430.

Lau FH, Wong AL, Lam PT, Lam DS. (2007). Photographic assay. Anterior segment Optical coherence tomography findings of early capsular block syndrome. Clin Experiment Ophthalmol, Vol. 35, No. 8, (Nov), pp. 770-771.

Lerche RC, Schaudig U, Scholz F, Walter A, Richard G. (2001). Structural changes of the retina in retinal vein occlusion-imaging and quantification with optical coherence tomography. Ophthalm Surg Lasers, Vol. 32, N0. 4, (Jul-Aug), pp. 272-280.

Li H, Leung CK, Cheung CY, -----(2007). Repeatabilty and reproducibility of anterior chamber angle measurement with anterior segment Optical coherence tomography. . Br J Ophthalmol, Vol. 91, No. 11, ( ), pp. 1490-1492.

Lincoff H, Kreissig I. (1998). Optical coherence tomography of pneumatic displacement of optic disc pit maculopathy. $\mathrm{Br}$ J Ophthalmol, Vol. 82, No. 4, (Apr), pp. 367372.

Lopez JM, Guerrero P. (2006). Congenital simple hamartoma of the retinal pigment epithelium: optical coherence tomography and angiography features. Retina, Vol. 26, No. 6, pp. 704-706.

Margherio RR, Trese MT, Margherio AR, Cartright K. (1989). Surgical management of vitreomacular traction syndromes. Ophthalmology, Vol. 96, No. 9, (Sept), pp. 14371445 .

Markomichelakis NN, Halkiadakis I, Pantelia E, Peponis V, Patelis A, et al. (2004). Patterns of macular edema in patients with uveitis: qualitative and quantitative assessment using Optical coherence tomography. Ophthalmology, Vol. 111, No. 5, (May), pp. 946-953.

Massin P, Allouch C, Haouchine B, Metge F, Pâques M, et al. (2000). Optical coherence tomography of idiopathic macular epiretinal membranes before and after surgery. Am J Ophthalmol, Vol. 130, No. 6, (Dec), pp. 732-739.

Mavrofrides EC, Cruz-Villegas V, Puliafito CA. Miscellaneous retinal diseases. In: Schuman JS, Puliafito CA, Fujimoto JG, eds. Optical coherence tomography of ocular diseases. Thorofare, NJ: SLACK, Inc.; 2004:457-482. 
Mavrofrides EC, Puliafito CA, Fujimoto JG. Central serous chorioretinopathy . In: Schuman JS, Puliafito CS, Fujimoto JG, eds. Optical coherence tomography of ocular diseases. Thorofare, NJ: SLACK, Inc; 2004:215-242.

Mavrofrides EC, Rogers AH, Truong S et al. Vitroretinal interface disorders. In: Schuman JS, Puliafito CA, Fujimoto JG, eds. Optical coherence tomography of ocular diseases. Thorofare, NJ: SLACK, Inc.; 2005: 57-102.

Mavrofrides EC, Villate N, Rosenfeld PJ et al.[eds]. Optical coherence tomography of ocular diseases. In: Schuman JS, Puliafito CA, Fujimoto JG [eds]. Optical coherence tomography of ocular diseases. Thorofare, NJ:SLACK, Inc.; 2004:243-343.

McDonald HR, Johnson RN, Schatz H. (1994). Surgical results in the vitreomacular traction syndrome. Ophthalmology, Vol. 101, No.8, (Aug), pp. 1397-1402.

Mori K, Gehlbach PL, Sano A, Deguchi T, Yoneya S. (2004). Comparison of epiretinal membranes of differing pathogenesis using optical coherence tomography. Retina, Vol. 24, No. 1, (Feb), pp. 57-62.

Moura FC, Medeiros FA, Monteiro ML. (2007). Evaluation of macular thickness measurements for detection of band atrophy of the optic nerve using optical coherence tomography. Ophthalmology, Vol. 114, No. 1, (Jan), pp. 175181.

Muscat S, Parks S, Kemp E, Keating D. (2004). Secondary retinal changes associated with choroidal nevi and melanomas documented by optical coherence tomography. $\mathrm{Br} \mathrm{J}$ Ophthalmol, Vol. 88, No. 1, (Jan), pp. 120-124.

Myer CH, Rodrigues EB, Schmidt JC. (2003). Congenital optic nerve head pit association with reduced retinal nerve fiber thickness at the papillomacular bundle. $\mathrm{Br} \mathrm{J}$ Ophthalmol, Vol. 87, No. 10, (Oct), pp. 1300-1301.

Panzan CQ, Guven D, Weiland JD, Lakhanpal R, Javaheri M, et al. (2004). Retinal thickness in normal and RCD1 dogs using optical coherence tomography. Ophthlm Surg Lasers Imaging, Vol. 35, No. 6, (Nov-Dec), pp. 485-493.

Parisi V, Manni G, Spadaro M, Colacino G, Restuccia R, et al. (1999). Correlation between morphological and functional retinal impairment in multiple sclerosis patients. Invest Ophthalmol Vis Sci, Vol. 40, No. 11, (Oct), pp. 2520-2527.

Pavlin CJ, Vasquez LM, Lee R, Simpson ER, Ahmed II. (2009). Anterior segment Optical coherence tomography and ultrasound biomicroscopy in the imaging of anterior segment tumors. Am j Ophthalmol, Vol. 147, No. 2, (Feb), pp. 214-219.

Pece A, Introini U, Bottoni F, Brancato R. (2001). Acute retinal pigment epithelial tear after photodynamic therapy. Retina, Vol. 21, No. 6, pp. 661-665.

Pekmezci M, Porco TC, Lin SC. (2009). Anterior segment Optical coherence tomography as a screening tool for the assessment of the anterior segment angle. Ophthalmic Surg Lasers Imaging, Vol. 40, No. 4, (Jul-Aug), pp. 389-398.

Pendergast SD, Hassan TS, Williams GA, Cox MS, Margherio RR, et al. (2000). Vitrectomy for diffuse diabetic macular edema associated with a taut premacular posterior hyaloid. Am J Ophthalmol, Vol. 130, No. 2, (Aug), pp. 178-186.

Poinooswamy D, Fontana L, Wu JX, Fitzke FW, Hitchings RA. (1997). Variation of nerve fibre layer thickness measurements with age and ethnicity by scanning laser polarimetry. Br J Ophthalmol,Vol. 81, No. 5, (May), pp. 350-354. 
Pulicken M, Gordon-Lipkin E, Blacer LJ, Frohman E, Cutter G, Calabreci PA. (2007). Optical coherence tomography and disease subtype in multiple sclerosis. Neurology Vol. 69, No. 22, (Nov), pp. :2085-2092.

Radhakrishan S, See J, Smith SD, Nolan WP, Ce Z, et al. (2007). Reproducibility of anterior chamber angle measurements obtained with anterior segment Optical coherence tomography. Invest Ophthalmol Vis Sci., Vol. 48, No. 8, (Aug), pp. 36833688 .

Robertson DM. (1986). Argon laser photocoagulation treatment in central serous chorioretinopathy. Ophthalmology, Vol. 93, No. 7, (Jul), pp. 972-974.

Rogers AH, Martidis A, Greenberg PB, Puliafito CA. (2002). Optical coherence tomography findings following photodynamic therapy of choroidal neovascularisation. Am J Ophthalmol, Vol. 134, No. 4, (Oct), pp. 566-576.

Roth AM, Foos RY. (1971). Surface wrinkling retinopathy in eye enucleated at autopsy. Trans Am Acad Ophthalmol Otolaryngol, Vol. 75, No. 5, (Sep-Oct) pp. 10471059.

Ryan SJ. Retina, $4^{\text {th }}$ edn, vol. 2. Elsevier Mosby 2006:1533-1556.

Sarodia U, Sharkawi E, Hau S, Barton K. (2007). Visualization of aqueous shunt position and patency using anterior segment Optical coherence tomography. Am $j$ Ophthalmol, Vol. 143, No. 6, (Jun), pp. 1054-1056.

Sato H, Kawasaki R, Yamashita H. (2003). Observation of idiopathic full-thickness macular hole closure in early postoperative period as evaluated by optical coherence tomography. Am J Ophthalmol, Vol. 136, No. 1, (Jul), pp. 185-187.

Schaudig UH, Glaefke C, Scholz F, Richard G. (2000). Optical coherence tomography for retinal thickness measurement in diabetic patients without clinically significant macular edema. Ophthalm Surg Lasers, Vol. 31, No. 3, (May-Jun) pp. 182-186.

Schuman JS, Puliafito CA, Fujimoto JG [eds]. Optical coherence tomography of ocular diseases. Thorofare, NJ: Slack; 2004.

Sekiryu T, Yamauchi T, Enaida H, Hara Y, Furuta M. (2000). Retina tomography after vitrectomy for macular edema of central retinal vein occlusion. Ophthalm Surg Lasers, Vol. 31, No. 3, (May-Jun), pp. 198-202.

Shukla D, Ambatkar S, Jethani J, Kim R.(2005). Optical coherence tomography in presumed congenital simple hamartoma of retinal pigment epithelium. Am. J. Ophthalmol, Vol. 139, No. 5, (May), pp. 945-947.

Sidd RJ, Fine SL, Owens SL, Patz A. (1982). Idiopathic preretinal gliosis. Am J Ophthalmol, Vol. 94, No. 1, (Jul), pp. 44-48.

Singh M, Chew PT, Friedman DS, Nolan WP, See JL et al. (2007). Imaging of trabeculectomy blebs using anterior segment Optical coherence tomography. Ophthalmology, Vol. 114, No. 1, (Jan), pp. 47-53.

Smiddy WE, Michels RG, Glaser BM, deBustros S. (1988). Vitrectomy for macular traction caused by incomplete vitreous separation. Arch Ophthalmol, Vol. 106, No 5, (May), pp. 624-628

Spirn MJ, Warren FA, Guyer DR, Klancnik JR, Spaide RF. (2003). Optical coherence tomography findings in nicotinic acid maculopathy. Am J Ophthalmol, Vol. 135, No. 6, (Jun), pp. 913-914. 
Srivastava SK, Sternberg P Jr. (2002). Retinal pigment epithelial tear weeks following photodynamic therapy with verteporfin for choroidal neovascularisation secondary to pathologic myopia. Retina, Vol. 22, No. 5 (Oct), pp. 669-671.

Stalmans P, Spileers W, Dralands L. (1999). The use of optical coherence tomography in macular diseases. Bull Soc Belge Ophthalmol, Vol. 272, pp. 15-30.

Suzuki T, Terasaki H, Niwa T. (2003). Optical coherence tomography and focal macular electroretinogram in eyes with epiretinal membrane and macular pseudohole. Am J Ophthalmol, Vol. 136, No. 1, (Jul), pp. 62-67

Teitelbaum BA, Tresley DJ. (2003). Cystic maculopathy with normal capillary permeability secondary to docetexel. Optom Vis Sci, Vol. 80, No. 4, (Apr), pp. 277-279.

Ting TD, Oh M, Cox TA, Meyer CH, Toth CA. (2002). Decreased visual acuity associated with cystoid macular edema in neovascular age-related macular degeneration. Arch Ophthalmol, Vol. 120, No. 6, (Jun) pp. 731-737.

Ullrich S, Haritoglou C, Gass C, Schaumberger M, Ulbig MW, Kampik A. (2002). Macular hole size as a prognostic factor in macular hole surgery. Br J Ophthalmol, Vol. 86, No. 4, (Apr), pp. 390-393.

Villate N, Mavrofrides EC, Davis J. Chorioretinal inflammatory diseases. In: Schuman JS, Puliafito CA, Fujimoto JG, eds. Optical coherence tomography of ocular diseases. Thorofare, NJ: SLACK, Inc.; 2004:371-412.

Voo I, Mavrofrides EC, Puliafito CA. (2004). Clinical applications of Optical coherence tomography for the diagnosis and management of macular diseases. Ophthalmol Clin North Am, Vol. 17, No. 1, (Mar), pp. 21-31.

Wang B, Sakata LM, Friedman DS, Chan YH, He M, et al. (2010). Quantitative iris parameters and association with narrow angles. Ophhalmology, Vol. 117, No. 1, (Jan), pp. 11-17.

Wilkins JR, Puliafito CA, Hee MR, Duker JS, Reichel E, et al. (1996). Characterisation of epiretinal membranes using optical coherence tomography. Ophthalmology, Vol. 103, No. 12, (Dec), pp. 2142-2151.

Wu R, Nongpiur ME, He MG, Sakata LM, Friedman DS, et al. (2011). Association of narrow angles with anterior chamber area and volume measured with anterior segment Optical coherence tomography. Arch Ophthalmol, Vol. 129, No.5, (May), pp. 569574.

Wylegala E, Teper S, Nowińska AK, Milka M, Dobrowolski D. (2009). Anterior segment imaging: Fourier-domain Optical coherence tomography versus time-domain Optical coherence tomography. Journal of cataract and refractive surgery, Vol. 35, No. 8, (Aug), pp. 1410-1414.

Yannuzzi LA, Ciardella A, Spaide RF, Rabb M, Freund KB, Orlock DA. (1997). The expanding clinical spectrum of idiopathic polypoidal choroidal vasculopathy. Arch Ophthalmol, Vol. 115, No. 4, (Apr), pp. 478-485.

Yannuzzi LA, Freund KB, Goldbaum M, Scassellati-Sforzolini B, Guyer DR, et al. (2000). Polypoidal choroidal vasculopathy masquerading as central serous chorioretinopathy. Ophthalmology, Vol. 107, No. 4, (Apr), pp. 767-777. 
Yannuzzi LA, Negrão S, lida T, Carvalho C, Rodriguez-Coleman H, et al. (2001). Retinal angiomatous proliferation in age-related macular degeneration. Retina, Vol. 21, No. 5, pp. 416-434.

Zacks DN, Johnson MW. (2004) Retinal angiomatus proliferation: optical coherence tomographic confirmation of an intraretinal lesion. Arch Ophthalmol, Vol. 122, No. 6, (Jun), pp. 932-933. 


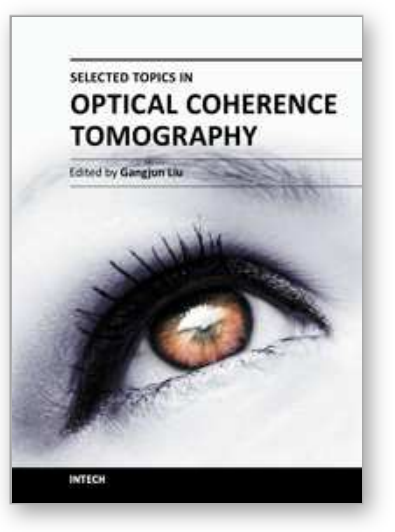

\author{
Selected Topics in Optical Coherence Tomography \\ Edited by Dr. Gangjun Liu
}

ISBN 978-953-51-0034-8

Hard cover, 280 pages

Publisher InTech

Published online 08, February, 2012

Published in print edition February, 2012

This book includes different exciting topics in the OCT fields, written by experts from all over the world. Technological developments, as well as clinical and industrial applications are covered. Some interesting topics like the ultrahigh resolution OCT, the functional extension of OCT and the full field OCT are reviewed, and the applications of OCT in ophthalmology, cardiology and dentistry are also addressed. I believe that a broad range of readers, such as students, researchers and physicians will benefit from this book.

\title{
How to reference
}

In order to correctly reference this scholarly work, feel free to copy and paste the following:

Upender K. Wali and Nadia Al Kharousi (2012). Clinical Applications of Optical Coherence Tomography in Ophthalmology, Selected Topics in Optical Coherence Tomography, Dr. Gangjun Liu (Ed.), ISBN: 978-953-510034-8, InTech, Available from: http://www.intechopen.com/books/selected-topics-in-optical-coherencetomography/clinical-applications-of-optical-coherence-tomography-in-ophthalmology

\section{INTECH}

open science | open minds

\author{
InTech Europe \\ University Campus STeP Ri \\ Slavka Krautzeka 83/A \\ 51000 Rijeka, Croatia \\ Phone: +385 (51) 770447 \\ Fax: +385 (51) 686166 \\ www.intechopen.com
}

\author{
InTech China \\ Unit 405, Office Block, Hotel Equatorial Shanghai \\ No.65, Yan An Road (West), Shanghai, 200040, China \\ 中国上海市延安西路65号上海国际贵都大饭店办公楼 405 单元 \\ Phone: +86-21-62489820 \\ Fax: $+86-21-62489821$
}


(C) 2012 The Author(s). Licensee IntechOpen. This is an open access article distributed under the terms of the Creative Commons Attribution 3.0 License, which permits unrestricted use, distribution, and reproduction in any medium, provided the original work is properly cited. 